Published in final edited form as:

J Pers Soc Psychol. 2014 January ; 106(1): 112-130. doi:10.1037/a0034950.

\title{
Personality and Self-Insight in Individuals with Autism Spectrum Disorder
}

\author{
Roberta A. Schriber, \\ Department of Psychology, University of California, Davis, Davis, CA, U.S.A \\ Richard W. Robins, and \\ Department of Psychology, University of California, Davis, Davis, CA, U.S.A \\ Marjorie Solomon \\ University of California, Davis School of Medicine, Department of Psychiatry, MIND Institute, \\ Imaging Research Center, Sacramento, CA, U.S.A
}

\section{Abstract}

\begin{abstract}
Autism spectrum disorder (ASD) involves widespread difficulties in social interaction, communication, and behavioral flexibility. Consequently, individuals with ASD are believed to exhibit a number of unique personality tendencies, including a lack of insight into them. However, surprisingly little research has examined these issues. Study 1 compared self-reports of Big Five personality traits in adults with ASD $(N=37)$ to those of typically developing (TD) adults $(N=42)$. Study 2 examined whether any observed personality differences replicated in children/adolescents with ASD $(N=50)$ and TD controls $(N=50)$ according to self- and parent reports. Study 2 also assessed level of self-insight in individuals with ASD relative to TD individuals by examining the degree to which self-reports converged with parent reports in terms of self-other agreement and self-enhancement (vs. self-diminishment) biases. Individuals with ASD were more Neurotic and less Extraverted, Agreeable, Conscientious, and Open to Experience. These personality differences replicated for (a) children, adolescents, and adults, (b) self- and parent reports, and (c) males and females. However, personality traits were far from perfect predictors of ASD vs. TD group membership, did not predict within-group variability in ASD symptom severity, and had differential links to maladjustment in the ASD and TD groups, suggesting that ASD represents more than just an extreme standing on trait dimensions. Finally, individuals with ASD had a tendency to self-enhance, and TD individuals, to self-diminish, but both groups showed comparable self-other agreement. Thus, individuals with ASD exhibit distinct personalities relative to TD individuals but may have a similar level of insight into them.
\end{abstract}

\section{Keywords}

autism; psychopathology; personality traits; personality judgment; self-knowledge

Please address correspondence to: Roberta A. Schriber, Department of Psychology, University of California, Davis. Phone: 713-410-4676. raschriber@ucdavis.edu. 
Imagine the child who perpetually sequesters himself from others due to social indifference or awkwardness. Or the one who, when venturing into a social interaction to express his fascination with Pokemon, is unable to interpret or act on the cues soon coming from his partner: Eyes dart around, an attempt to interject is issued, a glare, a sigh, a tapping foot, and, finally, the partner mentions needing to be somewhere else - and the child says he can tag along. Such a lack of attunement with and insight into others could easily foster atypical, even abrasive, personality characteristics in these children, who might not even know how they come across nor how to use that knowledge toward better ends. To the casual observer, they would seem socially aloof, avoidant, or unskilled; to one familiar with autism spectrum disorder (ASD), they would suggest the presence of that condition.

Autism was first described by Kanner (1943) in his study of eleven children with "autistic disturbances of affective contact" (p. 271), followed, independently, by Asperger (1944), who reported on a similar syndrome in four children in Vienna. Comprising a clinical phenotype that is highly variable in its form and severity, ASD - including "classic" autism, high-functioning autism (HFA), Asperger's syndrome, and pervasive developmental disorder not otherwise specified (PDDNOS) - is a neurodevelopmental disorder characterized, for the purpose of diagnosis, by early emerging (1) impairment in reciprocal social interaction, (2) difficulty in verbal and nonverbal communication, and (3) restricted or stereotyped patterns of interests and behavior (American Psychological Association, 2000). ${ }^{1}$ Within this "triad of impairments" (Rutter, 1968), social impairment has been considered the most debilitating and central to the disorder (Fein et al., 1986; Rogers, 2000).

Although individuals with ASD have been found to be atypical across many domains of functioning, the unique characteristics of individuals with ASD as manifested in their basic personality traits have received little empirical attention. Moreover, although individuals with ASD are assumed to be ignorant of their peculiar characteristics and to lack self-insight more generally (Frith \& Happé, 1999; Raffman, 1999), autism has never been investigated as a moderator of accuracy in judging one's own personality (i.e., trait self-knowledge). Indeed, researchers seldom assess the self-views of individuals with ASD, let alone evaluate their accuracy relative to some criterion for what they actually are like. Understandably, most work on ASD emphasizes clinically relevant goals, such as refining diagnostic criteria or evaluating the efficacy of different treatments, rather than seeking a deeper look at the personality and self-evaluative processes that might underlie the observed deficits. Thus, the present research investigates two questions about individuals with ASD: (1) how do their personalities differ from those of TD individuals; and (2) do they actually lack insight into their personalities, as is generally assumed?

\footnotetext{
${ }^{1}$ The revised ASD diagnostic criteria for the updated DSM-V places all variants of ASD diagnosis (e.g., Asperger's syndrome, highfunctioning autism) under the general umbrella of "autism spectrum disorder" and collapses the three criterion domains of social impairment, communication impairment, and fixated interests/repetitive behaviors into two: social/communication impairment and fixated interests/repetitive behaviors (APA, 2010). Recent work (Huerta, Bishop, Duncan, Hus, \& Lord, 2012) suggests the majority of individuals with DSM-IV ASD diagnoses are eligible for an ASD diagnosis under the revised criteria.
} 


\section{Do Individuals with Autism Have Unique Personalities?}

Children and adults with ASD are described as reluctant to make changes to their routines, as anxiety-prone, and as socially aloof or averse (Wing \& Gould, 1979), with their tending to treat social communications with no greater - and often less - priority than they do asocial stimuli (Mundy, Gwaltney, \& Henderson, 2010). Even when an interest in social interaction exists, individuals with ASD may lack the requisite skills to make a social encounter successful (Bauminger, Shulman, \& Agam, 2003). The debilitating interpersonal impairments experienced by individuals with ASD are assumed to result from a neurocognitive impairment in the basic motivation and ability to understand people's thoughts, feelings, and behaviors - perhaps even their own (Baron-Cohen, 2009; Chevallier et al., 2012; Perner et al., 1989; Hobson, 1993). Given the unique characteristics of individuals with ASD, it may be expected that their personality profile - that is, the distinct set of traits characterizing their typical patterns of thinking, feeling, and behaving - would be quite different from the modal personality profile of TD individuals.

Over the past few decades, individual differences in personality have increasingly been organized by researchers according to the Big Five model of personality (John, Naumann, \& Soto, 2008), with its dimensions having been linked to a wide range of real-world outcomes and psychological constructs (John et al. 2008; Ozer \& Benet-Martinez, 2006; Roberts, Kuncel, Shiner, Caspi, \& Goldberg, 2008), including personality disorders and other forms of psychopathology (Bastiaansen et al., 2011; Widiger \& Smith, 2008), for which there has been emerging interest in shifting from categorical to dimensional models of psychiatric classification (e.g., Adam, 2013; Cuthbert \& Insel, 2013; Krueger, Derringer, Markon, Watson, \& Skodol, 2011; Widiger \& Costa, 2012; Wright et al., in press). In fact, clinical science is currently at a critical juncture as the latest version of the DSM includes an option for making diagnoses based, in part, on assessing clients' maladaptive trait standings (Krueger et al., 2011; Widiger \& Costa, 2012). With increasing integration of normal and pathological personality, using the Big Five framework for investigating personality in ASD can help us understand personality more generally. We might ask, for example, how pervasively is personality altered in ASD, a disorder that has social impairment at its core? Are all traits affected? And how well is the ASD phenotype explained by describing personality? Based on what is known about the cognitive, affective, and behavioral features of ASD and in light of previous research, we can make several predictions about the Big Five traits of individuals with ASD.

First, we predict that individuals with ASD will be lower in Extraversion, given their difficulties with social interaction and communication and their tendency to avoid social contact rather than pursue it as rewarding (Mundy et al., 2010; Volkmar \& Klin, 2000). Second, we predict that individuals with ASD will be lower in Agreeableness due to their reduced capacity to comprehend interpersonal cues; to relate to, empathize with, and feel compassion for others; and to engage in emotionally sensitive, reciprocal social responding (Dawson et al., 2004; Hobson, Lee, \& Hobson, 2007; Mundy et al., 2010). Third, we predict that individuals with ASD will be lower in Conscientiousness, given their deficits in attentional shifting, working memory, inhibitory control, and other aspects of self-regulation (Hill, 2004; Solomon et al., 2008; Solomon et al., 2009). Indeed, the obsessional focus in 
ASD on narrow domains of interest might compromise more general aspects of Conscientiousness, such as the tendency to be organized, planful, and task-focused. Fourth, we predict individuals with ASD will be higher in Neuroticism, given their tendency to experience elevated levels of anxiety, anger, and emotional lability; to evidence poor emotion regulation; to develop internalizing and externalizing problems; and to exhibit pervasive social problems that might disrupt social support networks and contribute to feelings of alienation and loneliness (Capps, Kasari, Yirmiva, \& Sigman, 1993; White, Oswald, Ollendick, \& Scahill, 2009). Finally, we do not make a prediction about Openness to Experience. Although the behavioral rigidity and novelty-aversion of individuals with ASD imply lower Openness, the unique forms of creativity and hobbies that many individuals with ASD exhibit make the link between ASD and Openness tenuous.

Consistent with our predictions, the two published studies on Big Five traits in ASD - one conducted in Belgium with parents reporting on their 6-14 year-old children (De Pauw, Mervielde, Van Leeuwen, \& De Clercq, 2011) and the other conducted with adult outpatients screened for Asperger's syndrome in Japan (Kanai et al., 2011) - found lower Extraversion, Agreeableness, Conscientiousness, and higher Neuroticism, in ASD versus TD individuals. De Pauw et al. also found lower levels of Openness in ASD relative to TD individuals, whereas Kanai et al. found no group differences.

Notably, both studies relied on a single method to assess personality. De Pauw et al. used parent reports on the Hierarchical Personality Inventory for Children (HiPiC; Mervielde \& De Fruyt, 2002), which was in fact originally constructed from parents' open-ended descriptions of their children, and Kanai et al. used self-reports on a Japanese translation of the NEO Personality Inventory-Revised (NEO-PI-R; Costa \& McCrae, 1992). Thus, the effects in each study may have been biased by response styles and other methodological artifacts deriving from the limited perspective a single class of perceivers has on their targets (Paulhus \& Vazire, 2007; Vazire, 2010). For example, it might be unsurprising that Extraversion was the personality dimension that showed the largest group difference in De Pauw et al.'s study based on parent reports (i.e., an "outsider" perspective), whereas Neuroticism showed the largest group difference in Kanai et al.'s study based on self-reports (i.e., an "insider" perspective) (John \& Robins, 1993; Vazire, 2010). Moreover, Kanai et al.'s exclusive reliance on self-reports raises additional concerns: Given the abnormalities in language and social understanding in individuals with ASD, these individuals may interpret personality test items in idiosyncratic ways or may have particularly poor insight into their own personalities. To address these issues, we use both self- and parent reports of personality in children and adolescents with ASD vs. TD controls, allowing us to replicate the findings across assessment methods.

Additionally, we assessed personality in ASD children and adolescents as well as in adults using the same well-validated measure of the Big Five dimensions. Although the five-factor structure of the HiPiC used by De Pauw et al. (2011) is comparable to the Big Five, it is not perfectly commensurate with it (Mervielde, De Clercq, De Fruyt, \& Van Leeuwen, 2005). HiPiC Benevolence, for example, despite being analogous to Agreeableness, includes a Dominance facet that is more frequently associated with Extraversion and an Irritability facet that is more aligned with Neuroticism (Mervielde et al., 2005). Thus, the present 
research uses the Big Five Inventory (BFI; John, Naumann, \& Soto, 2008) to examine relations between autism and the core components of the Big Five. Using the same instrument across two age cohorts also allowed us to address an important question about the personality traits associated with autism: Are the personality differences observed in ASD and TD children evident in adults, or do ASD children seem to "grow out" of their potentially problematic personality tendencies?

Moreover, because ASD does not present identically with regard to its detection and severity across cultural, ethnic, racial, regional, and socioeconomic contexts (e.g., Matson et al., 2012; Norbury \& Sparks, 2013), differences driven, in part, by extensive variability in norms for social behavior and how autism itself is conceptualized and diagnosed, replication in a North American sample would support the generalizability of the previously observed personality differences. For example, higher levels of ASD symptom severity are generally reported in the United States compared to most other countries (Sipes et al., 2012). Perhaps consistent with this, the "high symptom severity" ASD group in De Pauw et al. (2011) was defined using a cut-off point on the Social Communication Questionnaire (SCQ; Rutter et al. 2003) that in the U.S. would be considered the minimum level for making an ASD diagnosis, and the "low symptom severity" group would not even receive an ASD diagnosis. Extending research on personality in ASD to the U.S. would tell us something about the cross-cultural generality of links between personality and ASD and thus help identify which personality traits are most clinically relevant to the disorder.

Aside from these methodological extensions, we also sought to move beyond simply describing ASD vs. TD differences in personality and ask how accurately we can predict whether or not an individual has an ASD based solely on their Big Five traits. Would knowing that a person is unusually introverted, disagreeable, disorganized, emotionally volatile, and restricted in their interests and behavior be sufficient to correctly classify him or her as having a clinical condition? Which traits would be most "diagnostic"? To address these questions, the present research uses discriminant function analysis (DFA), by which group membership can be predicted from all Big Five traits simultaneously and their relative influence assessed. DFA and other weighted classification techniques have been used with remarkable success (e.g., 95\% classification accuracy) to predict ASD diagnosis in individuals as young as 2-4 years old when predictors are relatively low-level biological factors such as whole and regional brain volumes (Akshoomoff et al., 2004) and pairs of electroencephalography (EEG) or magnetoenchephalography (MEG) signals coming from different areas of the brain (Domínguez, Velázquez, Galán, 2013; Duffy \& Als, 2012). The question, then, is how well can we predict ASD diagnosis using the Big Five framework, the most comprehensive and parsimonious framework available for summarizing phenotypic tendencies in thoughts, feelings, and behaviors?

Such an analysis capitalizes on the possibility that personality traits cross the threshold from normalcy to psychopathology and bears on the dimensional/categorical issue that has become a focus (and often source of controversy) in personality and clinical psychology whether psychological variation is best described in terms of degrees vs. kinds (cf. Meehl, 1992). Some researchers have argued that autism is a dysfunctional extreme of a "broader autism phenotype" that is normally distributed in the general population (Dawson et al., 
2002; Piven, Palmer, Jacobi, Childress, \& Arndt, 1997). However, a meta-analysis by Haslam, Holland, and Kuppens (2012) suggests that ASD may be one of the only syndromes of maladjustment to be best characterized as categorical, making an analysis of ASD within the dimensional framework of the Big Five potentially informative.

One step towards better understanding trait processes in ASD is to examine how traits relate to the phenotypic features of the disorder in individuals with and without ASD. If ASD is truly a categorical variable - that is, if it "carves nature at its joints," as Meehl put it - then we might expect personality differences to predict between but not within-group variability in autism symptom severity. In contrast, if autism comprises a continuum and the diagnostic cut-off used to categorize individuals as having vs. not having ASD is largely arbitrary creating a dichotomous category out of a continuous phenotype - then we would expect personality traits to predict within- as well as between-group differences in symptom severity. Autism provides a unique opportunity for studying such trait-pathology links given the tremendous diversity in its presentation; while one individual with ASD may be "socially aloof, completely mute, and locked into repetitive rocking and hand flapping," another may be "inappropriately over-friendly, highly verbal but incapable of distinguishing jokes from lies, and fascinated by abstruse astronomical facts" (Happé \& Charlton, 2012; p. 70). A related approach is to evaluate whether diagnostic status (i.e., having or not having ASD) moderates the relationship between traits and more general indices of maladjustment, such as externalizing and internalizing. If similar associations are found in the ASD and TD groups, then these groups, even if they differ on trait levels, could still be construed to lie on the same continuum of functioning.

With both approaches in mind, we examined how personality variation maps onto pathological variation by analyzing the degree to which the Big Five traits predict ASD symptom severity and general maladjustment (internalizing and externalizing symptoms) within the ASD and TD samples. Kanai et al. and De Pauw et al. correlated Big Five traits with ASD symptoms and/or general maladjustment, finding differential associations across the Big Five, but the same informant provided all relevant information. In contrast, the present research examines associations of parent- and self-reported Big Five traits with parent reports of ASD symptoms and maladjustment, and with clinician reports of ASD symptoms using the ADOS-G, a behavior-based diagnostic tool that has been found to be more sensitive and stable over time than parent reports (Lord, 2000). As such, the present research is the first to examine whether and the degree to which the Big Five traits predict clinical observation of ASD-related behaviors.

\section{Do Individuals with Autism Lack Self-Insight?}

Frith and Happé (1999) asserted that autism is "a devastating disorder because it disrupts not only understanding of others and their social relationships, but also understanding of self" (p. 19). Similarly, Zahavi (2010) noted that although autism is primarily associated with social deficits, "there is of course a long standing tradition - reflected in the very term 'autism' from the Greek term for self 'autos' - for also considering it as a disorder of self and self-understanding" (p. 547). To the extent that individuals with ASD are characterized by poor self-understanding, they should evidence inaccurate self-views, but researchers 
seldom assesses the self-views of individuals with ASD. Nevertheless, theory and research on autism suggest that individuals with ASD may have poor self-insight due to deficiencies in three main capacities: (1) the capacity to introspect on their internal thoughts and feelings; (2) the capacity to use concepts and language crucial for building self-knowledge; and/or (3) the capacity to engage in social interactions that advance self-knowledge through the opportunity to internalize others' views of them.

First, although Theory-of-Mind deficits are well-known in ASD (cf. Baron-Cohen, Leslie, \& Frith, 1985; Yirmiya, Erel, Shaked, \& Solomonica-Levi, 1998), individuals with ASD are also purported to have deficits in basic self-awareness and introspective capacity - aspects of psychological functioning without which self-insight should be difficult to attain (Morin, 2011; Trapnell \& Campbell, 1999). Several researchers (Baron-Cohen, 2003; Frith \& Happé, 1999; Lombardo \& Baron-Cohen, 2011) posit that the neurocognitive mechanism that is impaired in ASD enables the attribution of mental states not only to others but also to oneself. Thus, to the extent that individuals with ASD have trouble grasping or gleaning others' thoughts, feelings, intentions, motivations, beliefs, attitudes, and so on, they are thought to lack immediate rapport with their own, even needing to infer them from their own behavior in the same rigid, rule-based fashion they apply to others. This impairment, termed "mindblindness" (Baron-Cohen, 1995; Carruthers, 1996), has been inferred from such findings as that high-functioning individuals with ASD do not report on second-order thoughts when asked about their mental contents, instead tending to convey visual imagery mostly related to first-order experience (Frith \& Happé, 1999), and that brain regions related to introspection and mentalizing, which overlap (Lombardo et al., 2010), either function abnormally in individuals with ASD (Assaf et al., 2010; Di Martino et al., 2009) or give rise, when damaged, to characteristics consistent with the disorder (Umeda, Mimura, \& Kato, 2010).

The second, less extreme, perspective suggests that individuals with ASD do not lack introspective capacity but the ability to use meta-representational concepts needed for understanding and organizing their introspections (Leslie \& Thaiss, 1992; Perner, 1991). This deficit - called "conceptual incompetence" by Raffman (1999) - should impair the ability of individuals with ASD to form conceptually complex and elaborated representations of their personal attributes, let alone accurate ones. That is, if individuals with ASD are unable to crystallize their self-reflections, they should be less able to develop, over time, the richly connected semantic and experiential associations that contribute to selfknowledge and its report. Consistent with this possibility, individuals with ASD are often characterized by alexithymia - literally meaning "having no words for emotions" - and have difficulty describing their emotional experience despite showing typical emotional reactions in other respects (Ben Shalom et al., 2006; Berthoz \& Hill, 2005).

Finally, individuals with ASD may be unwilling or unable to engage in the type of social interaction that promotes the attainment of accurate self-knowledge. As Hobson (2002) suggested, developing self-knowledge depends on the ability to adopt another's attitude towards oneself, itself mediated by insight into another's reactions to oneself during interpersonal exchanges. This view, complemented by impaired Theory-of-Mind deficits in ASD, aligns with the symbolic interactionist idea of the "looking-glass self" (Cooley, 1902; 
Mead, 1934; Schrauger \& Schoeneman, 1979), whereby people come to know themselves through the eyes of others and come to internalize those views. Given that individuals with ASD tend to shy away from social contact altogether and often fail to understand others' social cues, they may lack sufficient means for accruing knowledge about themselves through the knowledge that others mirror about them.

So far, we have outlined ways in which self-insight might be impaired in autism according to theories of autism. However, several lines of theory and research from the literature on personality judgment also inform our predictions. Funder (e.g., 1995, 1999) organized moderators of accuracy in personality perception into four main categories, which he labeled (1) good judge, (2) good target, (3) good trait, and (4) good information. ASD complicates features related to each of these. We might expect individuals with ASD to be poor judges of personality - including their own - given their pervasive deficits in social-cognitive processing. We might also expect them to be poor targets - including their own - because of the very nature of the personality to be judged. They appear to be neither extraverted nor well-adjusted, both qualities of targets who are accurately judged, with extraversion entailing expressing a wealth of information about oneself, and well-adjustment ensuring such information is coherent, consistent across contexts, and easy to decode (Colvin, 1993; Funder, 1995). With regard to traits, although traits that are high in observability and evaluativeness are typically the most difficult for the self to judge accurately (John \& Robins, 1993; Vazire, 2010), ASD may (1) confer equal disadvantage for judging external vs. internal traits due to the aforementioned possibility of deficient self-consciousness, yet also (2) inoculate individuals from biases coming from the need to be favorably evaluated by the self or other, given their lack of social motivation and concern about reputation (Izuma et al., 2011). The net effect would be poor self-insight and possibly even less differentiation across traits regarding those for which ASD individuals have more or less self-knowledge. Finally, ASD could hinder good information. For instance, the social aversion and behavioral inflexibility of individuals with ASD would limit the situations in which they can express and monitor their personalities.

It is possible to go further with these presumed shortcomings when one takes into account the six unique two-way interactions among the moderating factors (Funder, 1995). Consider autism and judging one's own Conscientiousness. The Judge $\times$ Trait interaction denotes Expertise, but individuals with ASD, who have poor executive functioning, are unlikely to be finely attuned to or invested in judging the myriad criteria relevant to Conscientiousness - unlike, say, an emerging entrepreneur whose life pivots around persistence, organization, efficiency, meeting goals, and keeping abreast of these qualities in other people. Regarding Trait $\times$ Information, which deals with Diagnosticity, certain attributes in ASD, like preferring work that is routine, paying attention to detail, and being rule-abiding, might seem germane to Conscientiousness when, in actuality, they take on vastly different meanings in the context of the disorder. Altogether, then, a range of perspectives suggests that individuals with ASD will show worse self-insight than TD individuals. Despite this rich array of relevant theory, there is a dearth of empirical research on the topic.

Luckily, the literature on personality judgment also gives us the methodological tools we need to address the issue of self-insight in ASD. The most common approach to evaluating 
accuracy of self-perception is to compare self-reports of personality with those provided by knowledgeable informants. In the present research, we use parent reports of Big Five traits as a criterion for evaluating the accuracy of ASD and TD youths' self-reports of their Big Five traits. Although parent reports have their own limitations (e.g., parents may provide overly rosy descriptions of their children), they do provide one external source of information that can be used to evaluate the veracity of children's self-views. Once collected, self and informant reports can be compared in terms of relative agreement (i.e., selfinformant correlations) and directional deviations (i.e., self-informant discrepancies), which provide somewhat different information (Schriber \& Robins, 2012).

With regard to relative agreement, both variable- and person-centered approaches are available (Furr, 2010). A variable-centered approach assesses self-other agreement by computing, across persons, a self-informant correlation for each trait. This measure reflects the degree to which self and informants agree about the rank-ordering of targets on each trait. In contrast, a person-centered approach assesses self-other agreement separately for each person by computing, across the set of traits, a correlation between the trait profiles rated by self and informant. This measure of overall profile agreement reflects the degree to which self and informant agree about the rank-ordering of traits within an individual (i.e., which traits are relatively descriptive, or non-descriptive, of the target). However, high profile agreement can sometimes be achieved when a judge rates a target as if she were simply a typical member of her group (Furr, 2010), so this index is further decomposed into distinctive agreement, reflecting the degree to which a target and judge agree about the unique aspects of a target's trait profile relative to the group average, and two indices of normative agreement that respectively gauge (1) how much a target's self-rated profile converges with the average target-rated profile, and (2) how much an informant-rated profile converges with the average informant-rated profile. By simultaneously examining distinctive and normative agreement, we should be able to directly assess the extent to which ASD and TD individuals agree with informants regarding their profile of unique,

differentiating traits as opposed to simply the profile of traits likely to define them based on group membership. We predict individuals with ASD will show worse self-other agreement than TD individuals according to both variable- and person-centered approaches.

With regard to directional deviations, although high self-informant correlations, both variable- and person-centered, suggest greater self-insight, neither provides information about systematic biases. That is, high self-informant correlations can be obtained even when self-reports are systematically more positive (or negative) than informant reports. Thus, to complement self-informant correlations, self-reports can also be compared to other-reports in terms of directional deviations, whereby positive discrepancies for favorable attributes indicate self-enhancement, and negative discrepancies, self-diminishment. Based on research showing that individuals with ASD report their psychiatric symptoms to be less severe than they actually are (Koning et al., 2001; Johnson et al., 2009), we predict that individuals with ASD will show a positivity bias relative to parent reports of their personality. Altogether, these various measures of agreement and bias provide a comprehensive test of the degree to which individuals with ASD exhibit poor self-insight relative to TD individuals. 


\section{The Present Research}

The present research had two broad aims: (1) to investigate personality differences between ASD and TD individuals, and (2) to investigate whether ASD individuals have less insight into their personalities than do TD individuals. In Study 1, we examined group differences in self-reported personality traits between adults with and without ASD, then examined the degree to which personality traits (1) predicted ASD vs. TD group membership and (2) explained variability within the ASD group in clinician-rated ASD symptoms. Study 2 extended Study 1 in three main ways. First, we examined personality-ASD relations in a sample of children and adolescents rather than adults. Second, we used both self- and parent-reports of the Big Five, allowing us to rule out the possibility that self-report response-style differences might account for the ASD vs. TD differences in personality. Third, we examined the personality correlates of within-group variability in general maladjustment (internalizing, externalizing) as well as in ASD symptom severity, and we did so in the TD group as well as in the ASD group. Finally, Study 2 also addressed the question of self-insight by looking at the degree to which the self-reports of children and adolescents with and without ASD converge with parent reports in terms of accuracy (selfinformant correlations from variable- and person-centered approaches) and selfenhancement bias (positive discrepancies between self and informant reports).

\section{Study 1}

The majority of research on ASD has been limited to children and adolescents, despite understanding of autism as a developmental disorder and despite calls for researchers to examine ASD in adulthood (Borthwick, 2012). Thus, we first examined how the personality traits of adults diagnosed with ASD differ from the personality traits of an age- and gendermatched sample of TD individuals. It is possible that individuals with ASD develop more positive personality characteristics as they learn skills and strategies that help them adapt to the social world (Seltzer, Shattuck, Abbeduto, \& Greenberg, 2004), perhaps especially if they have already received the benefit of an earlier diagnosis (Makrygianni \& Reed, 2010). Investigating personality in adults with ASD would shed light on the implications of autism for adulthood, when individuals are faced with the developmental task of learning to support themselves in order to live independently and are establishing nurturing, meaningful relationships. As such, it could also help "tailor treatments, interventions, and services and supports to the evolving needs of adolescents transitioning to adulthood and adults across the spectrum with ASD" (IACC, 2010, p. 39).

To assess the robustness of any observed differences, we examined whether they (a) hold after controlling for group differences in IQ, and (b) are moderated by sex. The extreme male-brain theory of autism (Baron-Cohen, 2002) raises the possibility that TD individuals will show larger gender differences in personality relative to individuals with ASD, as the latter group might be characterized by more uniformly "male" features.

\section{Method}

Participants-Participants were 37 (22\% female) individuals with ASD ( $M$ age $=22.2$ years, $S D=5.5$; range $=18$ to 40 years $)$ and $42(20 \%$ female $)$ TD individuals $(M$ age $=23.2$ 
years, $S D=4.2$; range $=18$ to 34 years), all with Wechsler Full Scale IQ $\geq 79$ (WASI; Wechsler, 1999). Of the ASD sample, 29\% were diagnosed with high-functioning autism (HFA), 57\% with Asperger's syndrome, and 14\% with PDDNOS, according to criteria set by the DSM-IV-TR (American Psychiatric Association, 2000), assessment via the Autism Diagnostic Observation Schedule-Generic (Lord et al., 2000), a prior community diagnosis, and a psychosocial interview. We included individuals with varied diagnoses because it is difficult to reliably distinguish among these disorders, and there is no empirical distinction in symptomatology or outcome by the age of 8 years (the age of the youngest participants in the current research; e.g., Ozonoff \& Griffith, 2000). Individuals with diagnoses of autism with known genetic etiologies and psychopathology were excluded.

Participants were recruited from local physicians, psychologists, speech and language pathologists, occupational therapists, advocacy groups, regional centers, ASD support groups, and the M.I.N.D. Institute's Subject Tracking System, which includes children and adults with developmental disorders as well as TD children and adults who serve as control samples. TD participants could have no current or history of psychiatric disorders, including neurodevelopmental disorders, other than learning disabilities.

The ASD $(M=108, S D=16.1$; range $=79$ to 140$)$ and TD groups $(M=116, S D=12.1$; range $=87$ to 136) differed in Full Scale IQ scores, $t=2.3, p<.05$. Given this difference, we will examine whether any observed personality differences between the ASD and TD groups hold after controlling for IQ.

\section{Measures}

Autism Diagnostic Observation Schedule-Generic (ADOS-G; Lord et al., 2000): To confirm diagnosis and to provide a relatively objective, behavior-based measure of current ASD symptoms, participants with ASD were administered module 3 or 4 (based on language ability) of the ADOS-G by a trained clinician. The ADOS-G is a semistructured protocol that offers standardized observation of social interaction, communication, play, and imaginative use of materials. Planned situations called "presses" are created which allow a range of spontaneous behavior to be elicited. Participants are rated based on their behavioral responses and scored for reciprocal social behavior, communication, and repetitive and stereotyped interests and behavior. An algorithm score that combines the reciprocal social interaction and communication domains is the basis for diagnostic classification. Lord et al. (2000) showed mean inter-rater agreement was $88 \%$ across all items for modules 3 and 4. Scores ranged from 7 to 22 with a mean of 11.6 and standard deviation of 3.6.

Wechsler Abbreviated Scale of Intelligence (WASI; Wechsler, 1999): The four-subtest version of the WASI was used to provide a short and reliable means of assessing intelligence. It consists of four subtests (Vocabulary, Block Design, Similarities, and Matrix Reasoning) and produces Verbal (VIQ), Performance (PIQ), and Full Scale IQ (FSIQ) scores. These scales provide standard scores with a mean of 100 and a standard deviation of 15. The WASI is nationally standardized and has strong psychometric properties. The testretest reliability of the IQ scales ranges from .88 to .93 . Participants were required to have FSIQ scores above 75. 
Big Five Personality Traits (BFI; John et al., 2008): The Big Five personality dimensions were assessed using the 44-item BFI, which shows high convergent validity with other selfreport measures of the Big Five dimensions (John et al., 2008). Participants rated items on a 5-point Likert scale ranging from 1 "disagree strongly" to 5 "agree strongly." In the present sample, alpha reliabilities for Extraversion, Agreeableness, Conscientiousness, Neuroticism and Openness to Experience, respectively, were, in the ASD sample, .85, .78, .79, .85, and . 72 , and, in the TD sample, $.81, .54, .72, .83$, and .84 . The low alpha for Agreeableness in the TD group was unexpected and may have been driven, in part, by a ceiling effect coupled with low variances on some items, but the source is ultimately unclear. At the scale level, there were no significant group differences in variance for any of the Big Five, except that ASD adults, as compared to the TD adults, had significantly more variability in their Extraversion ratings, based on Levene's test for homogeneity of variance, $F(1,77)=5.24, p$ $<.05$.

\section{Results and Discussion}

\section{Do ASD and TD adults have different personality trait levels?-We first} examined whether ASD and TD individuals showed different personality trait levels. Compared to TD adults, ASD adults tended to be more Neurotic and less Extraverted, Agreeable, Conscientious, and Open to Experience (see Table 1). These personality differences were generally "large" in magnitude according to Cohen's (1988) rules of thumb, ranging from a standardized mean difference of .55 for Openness to a difference of .90 for Conscientiousness, with a median $d$ of $.84 .^{2}$ All effects remained significant when IQ was entered as a covariate. To test whether these personality differences varied as a function of sex, we conducted a series of 2-way ANOVAs with Group (ASD vs. TD) and Sex (Male vs. Female) as between-subjects factors. The Group $\times$ Sex interaction was nonsignificant for all Big Five dimensions, indicating that the personality differences between ASD and TD adults were similar for men and women. ${ }^{3}$

\section{How well do personality traits predict ASD vs. TD group membership?-We}

next examined how well personality traits alone could be used to predict whether individuals did or did not have an ASD diagnosis - that is, whether they belonged to the ASD or TD group. A discriminant function analysis was performed using the Big Five traits as predictors of ASD vs. TD group membership. The discriminant function was significant (Wilks' lambda $=.697, \chi^{2}(5)=26.49, p<.001$ ), with a canonical correlation of .55, indicating that the model accounted for $30.3 \%$ of the between-group variance. Results suggest that Neuroticism, with a standardized discriminant function coefficient of -.38 , was the best predictor of group membership, followed by Agreeableness, .37;

Conscientiousness, .37; Openness, .26; and Extraversion, .23. Overall, the model correctly

\footnotetext{
${ }^{2}$ We also examined whether group differences emerged at the facet level (Soto \& John, 2009), for which the BFI includes facets of: Assertiveness and Activity (Extraversion); Altruism and Compliance (Agreeableness); Order and Self-Discipline (Conscientiousness) Anxiety and Depression (Neuroticism); and Ideas and Aesthetics (Openness). In Study 1, all trait-level group differences replicated at the facet level, except no group difference was found for Aesthetics. In Study 2, all trait-level group differences replicated at the facet level for parent reports, but were not significant for Assertion, Order, or Aesthetics, and only marginally significant for Depression, $p$ $=.10$, in child self-reports. Repeated-measures ANOVAs, with Group (ASD vs. TD) as the between-subjects factor and Facet as the within-subjects factor, revealed no Group $\times$ Facet interactions in either study.

${ }^{3}$ In both Studies 1 and 2, all ASD vs. TD differences in personality remained significant after controlling for age as well.
} 
classified individuals as ASD vs. TD 70\% of the time. These results suggest that personality predicts diagnostic status reasonably well, but clearly more goes into differentiating the ASD and TD groups than personality.

Do personality traits predict within-group variability in ASD symptom severity in the ASD group?-The previous sets of analyses investigated the degree to which personality traits are associated with the between-group diagnosis of ASD vs. TD. Here, we explore whether personality traits predict within-group variability in ASD symptom severity based on behavioral observation in individuals diagnosed with ASD. In other words, do individuals with more severe ASD symptoms have different personality traits than individuals with milder ASD symptoms? Table 2 shows correlations between adults' selfrated Big Five traits and clinician-rated ASD symptomatology using the ADOS. A multiple regression analysis simultaneously entering all Big Five traits as predictors of total ADOS score was not significant $\left(R^{2}=.23, F=1.825, n s\right)$. Only Neuroticism was significantly related to ASD symptom severity, $r=-.37$, but higher levels of Neuroticism predicted less, not more, severe symptoms. This counterintuitive result should be treated with caution, however, because it became nonsignificant when we eliminated the three outliers with standardized residuals greater than two standard deviations from the regression line, indicating that the effect is driven by a relatively small number of cases. Moreover, as will be seen in Study 2, the corresponding correlation is not significant in the child/adolescent sample. Overall, the results suggest that personality does not significantly contribute to within-group variability in ASD symptomatology in individuals diagnosed with ASD, a conclusion that is further bolstered by the findings to be reported in Study 2 .

Taken together, the findings from Study 1 support predictions based on previous theory and research, and suggest that personality differences between ASD and TD individuals are evident in adulthood. However, findings indicate that personality, while successful at distinguishing between diagnostic groups, generally does not significantly distinguish between individuals with ASD who are experiencing more or less severe symptoms.

\section{Study 2}

Study 2 examined whether the personality differences observed in Study 1 replicate (1) in a sample of children and adolescents with ASD as well as (2) for self and parent reports of personality. Study 2 also continued to explore how personality relates to maladjustment. We again examined how traits relate to variability of clinician-rated ASD symptoms in individuals diagnosed with ASD. In addition, because the possibility of a broader autism phenotype that is normally distributed in the general population encourages testing for, and even expecting, similar trait-pathology links in the ASD and TD samples, we examined how Big Five traits relate to within-group variability of ASD symptoms in both groups using parental ratings of ASD symptoms. Finally, we extended these trait-maladjustment analyses to looking at how traits relate to more general indices of maladjustment (i.e., internalizing and externalizing) as rated in both groups by parents.

The other purpose of Study 2 was to examine whether individuals with ASD have insight into their personality traits. Replication of results across self- and parent reports would hint 
at "yes", but we can more directly use these data to test this enduring issue in ASD using parent reports as a criterion measure for evaluating accuracy and bias in the self-perceptions of individuals with and without ASD. Based on both the autism and personality judgment literatures, we expected individuals with ASD to show less self-insight, both in terms of self-informant agreement and self-enhancement.

Method

Participants-Participants were 50 (58\% female) individuals with ASD ( $M$ age $=12.1$ years, $S D=3.4$, range $=8$ to 18$)$ and $50(60 \%$ female $)$ TD individuals $(M$ age $=12.0, S D=$ 3.0, range $=8$ to 18 ), all with FSIQ $\geq 75$ (WASI; Wechsler, 1999). The recruitment strategy and inclusion and exclusion criteria were the same as in Study 1. Of the ASD sample, 56\% were diagnosed with HFA, 24\% with Asperger's syndrome, and 20\% with PDDNOS, according to criteria set by the DSM-IV-TR, using the ADOS-G, and a score above 15 on the Social Communication Questionnaire (SCQ; Rutter, Bailey, \& Lord, 2003). The ASD $(M \mathrm{~s}=104, S D=16.3$, range $=75$ to 145$)$ and TD groups $(M=117, S D=12.9$, range $=88$ to 139) differed in FSIQ scores, $t=4.2, p<.01$. Given this difference, we will examine whether any observed personality differences between the ASD and TD groups hold after controlling for IQ. Also, one unique feature of the design in this study's design was the approximately equal proportion of males to females in the ASD sample, rather than the 4:1 ratio typically seen in the ASD population (Fombonne, 2003). This provided us with more power for testing whether gender moderated any of the observed differences in personality.

Measures: As in Study 1, the WASI was used to assess intelligence, the ADOS-G was used to assess ASD-related behaviors, and the BFI was used to assess the Big Five personality dimensions. Similar to the adult sample, ADOS-G scores ranged from 7 to 22 with a mean of 10.7 and standard deviation of 3.5. The BFI has been validated for use by children as young as 10 (Soto et al., 2008). Both participants and their parents rated the BFI items on a 5-point Likert scale ranging from 1 "disagree strongly" to 5 "agree strongly." The parent reports were provided by mothers (85\%), fathers (12\%), grandmothers (1\%), brothers (1\%), and sisters (1\%). One participant from the TD sample was missing a parent report and thus could not be included in analyses on self-other agreement and directional deviations. In the present sample, alpha reliabilities for child self-reports in the ASD and TD samples, respectively, were .44 and .84 for Extraversion, .72 and .77 for Agreeableness, .63 and .74 for Conscientiousness, .67 and .62 for Neuroticism, and .63 and .67 for Openness to Experience, indicating comparable reliability in the two samples except for Extraversion. ${ }^{4}$ For parent reports, alpha reliabilities in the ASD and TD samples, respectively, were .88 and .86 for Extraversion, .89 and .76 for Agreeableness, .89 and .87 for Conscientiousness, . 87 and .82 for Neuroticism, and .82 and .78 for Openness to Experience. Child self-reports of Extraversion had significantly less variance in the ASD vs. TD group, $F(1,98)=5.70, p$ $<.05$. In contrast, parent reports in the ASD group showed significantly more variance for

\footnotetext{
${ }^{4}$ Although the BFI has not been validated for children under 10, alpha reliabilities in the subsample of 8-and 9-year old children reached satisfactory levels (albeit somewhat lower than in the full sample), ranging from .44 (Extraversion) to .77 (Agreeableness) for self- reports and from .87 (Extraversion) to .91 (Neuroticism) for parent reports.
} 
Extraversion, $F(1,98)=7.03, p<.01$, Agreeableness, $F(1,98)=30.34, p<.001$, and Openness, $F(1,98)=5.75, p<.05$.

Social Communication Questionnaire (SCQ; Rutter et al., 2003): One of the participant's parents completed the SCQ, a 40-item questionnaire to evaluate communication and social skills. It contains parallel questions to those on the ADI-R (Lord, Rutter, \& LeCouteur, 1994), the gold standard parent-report diagnostic measure, but in a briefer format. Berument, Rutter, Lord, Pickles, and Bailey (1999) reported that a cutoff of 15 gave sensitivity of .96 and specificity of .80 for autism vs. other diagnoses. Thus, a cutoff of 15 was used.

\section{Behavior Assessment System for Children, Second Edition (BASC-2; Reynolds \&}

Kamphaus, 2004): Internalizing and externalizing problems were assessed by parent report on the BASC-2. The BASC-2 has been used to evaluate problem behaviors in individuals ranging from age 2 to 25 years, and has acceptable levels of test-retest (.76 to .84$)$ and alpha reliability (.80 to .87$)$. Internalizing was computed as a composite of the Anxiety, Depression, and Somatization scales; externalizing was computed as a composite of the Aggression, Hyperactivity, and Conduct Problems scales.

\section{Results and Discussion}

\section{Do ASD and TD children and adolescents have different personality trait} levels?-Consistent with previous research and what we observed in the adult sample in Study 1, ASD children and adolescents tended to be more Neurotic and less Extraverted, Agreeable, Conscientious, and Open to Experience than TD children and adolescents (see Table 3). The effect sizes were "moderate" to "large" in magnitude, ranging from .37 for Openness in child self-reports to 1.84 for Neuroticism in parent reports; Neuroticism also showed the largest group difference in child self-reports. All of the personality differences replicated for self and parent reports, except that the difference in Openness between ASD and TD children did not hold in self-reports. The effect sizes were larger for parent reports (median $d=1.19$ ) than for self-reports (median $d=.48$ ).

To test whether the personality differences varied as a function of sex, we conducted a series of 2-way ANOVAs with Group (ASD vs. TD) and Sex (male vs. female) as betweensubjects factors predicting self and parent reports of each Big Five dimension. In all 10 analyses, the Group $\times$ Sex interaction was nonsignificant, indicating that the personality differences between ASD and TD children were similar for boys and girls.

Finally, we tested whether these personality differences held after controlling for IQ. All of the effects remained significant when IQ was entered as a covariate, except that the group difference in self-reported Conscientiousness became marginally significant, $p<.10$.

\section{How well do personality traits predict ASD vs. TD group membership?-To}

examine how well personality traits predict presence or absence of ASD diagnosis (i.e., ASD vs. TD group membership), discriminant function analyses were performed separately for child self-reports and parent reports using the Big Five traits as predictors. For both sets of reporters, the discriminant function was significant (in children: Wilks' lambda $=.827$, $\chi^{2}(5)=17.90, p<.01$, with a canonical correlation of .42 ; in parents: Wilks' lambda $=.484$, 
$\chi^{2}(5)=68.56, p<.01$, with a canonical correlation of .72). Results suggest that for each set of reporters, Neuroticism was the best predictor of group membership. Standardized discriminant function coefficients for each trait were, for child self-reports: Neuroticism, - . 61; Openness, .34; Extraversion, .31; Agreeableness, .25, and Conscientiousness, .08; and, for parent reports: Neuroticism, -.64; Conscientiousness, .30; Openness, .24;

Agreeableness, .13; and Extraversion, .07. For child self-reports, the model correctly predicted $69 \%$ of the cases. For parent reports, the model correctly predicted $83 \%$ of the cases. Thus, as with the DFA in the adult sample, results suggest that diagnostic status is somewhat, but far from entirely, explained by Big Five trait levels.

\section{Do personality traits predict within-group variability in ASD symptom severity} in the ASD and TD groups?-As in Study 1, we investigated how Big Five traits relate to ASD symptoms within the ASD sample by examining correlations of self- and parentreported Big Five traits with clinician-reported ASD symptoms on the behavior-based ADOS (see Table 2). No personality traits for either set of reporters were significantly related to total ADOS score. For children and parents, respectively, a multiple regression model simultaneously entering all Big Five traits as predictors of total ADOS score was not significant (for children: $R^{2}=.08, F=.772, n s$; for parents: $R^{2}=.04, F=.414, n s$ ). Thus, regardless of the reporter of personality, personality traits did not predict individual differences in observed ASD symptomatology within a group of children and adolescents diagnosed with ASD.

We were able to further explore this question using a second measure of autism symptom severity, the parent-reported SCQ, which was assessed in the TD sample as well as in the ASD sample. To avoid problems with shared method variance, we focus here on the findings for child-reported personality traits. As Table 2 shows, none of the Big Five traits showed significant correlations with SCQ symptom severity in either the ASD or TD groups, replicating the results obtained for the ADOS and extending the findings from Study 2.

\section{Which personality traits are associated with general maladjustment in the ASD vs. TD groups?-Table 4 shows correlations of the Big Five traits with} internalizing and externalizing symptoms within the ASD and TD groups. In contrast to the results for symptoms specific to ASD (as measured by the ADOS and SCQ), many of these within-group correlations were significant. However, the pattern of findings was somewhat different for the two groups. A moderated multiple regression analysis with the ASD and TD groups pooled together showed that diagnostic status (ASD vs. TD) significantly moderated the effect of Agreeableness on internalizing and the effect of Neuroticism on both internalizing and externalizing. Specifically, lower self-reported Agreeableness was related to more internalizing in the ASD group, $r=-.34, p<.05$, whereas the association in the TD group, although nonsignificant, was in the opposite direction, $r=.22$, ns. Also, Neuroticism according to both sets of reporters was much more strongly associated with internalizing and externalizing in the ASD group relative to the TD group (see Table 4 for correlations), and, when self-reported, even had a tendency to negatively predict externalizing in the TD group. 
It is noteworthy that internalizing and externalizing symptoms were themselves correlated . $48(p<.01)$ in the ASD group and only .28 $(p=.05)$ in the TD group, suggesting that children and adolescents with ASD are more likely to co-experience symptoms of these different forms of psychopathology. Also, as would be expected, individuals with ASD relative to TD individuals were characterized by more internalizing $(M=64.53, S D=15.17$, vs. $M=45.24, S D=8.06, t(95)=7.825, p<.01)$ and more externalizing $(M=60.23, S D=$ 12.40 , vs. $M=43.67, S D=5.31, t(95)=8.567, p<.01)$.

\section{Do ASD individuals show less self-insight than TD individuals?}

Self-other agreement using a trait-centered approach: We first examined whether selfother agreement correlations between self and parent reports of personality were significant for each of the Big Five traits, across the total sample and separately for the ASD and TD samples (see Table 5). Counter to the prediction of poor self-insight in ASD individuals relative to TD individuals, agreement correlations were statistically significant for almost all of the Big Five traits, except Conscientiousness, in the ASD sample, and, similarly, for almost all of the Big Five traits, except Neuroticism, in the TD sample. In the ASD sample, correlations between self- and parent reports were moderately positive, ranging from .19 for Conscientiousness to .42 for Neuroticism, with a median of .34. In the TD group, the correlations were moderate to high, ranging from .23 for Neuroticism to .71 for Extraversion, with a median of .38 . According to a $z$-test of the difference between independent correlations, the only significant group difference was for Extraversion, for which TD children and their parents showed substantially higher levels of agreement than ASD children and their parents. Thus, except for the Extraversion domain, ASD and TD children tended to show similar levels of agreement with their parents about their personality tendencies.

\section{Self-other agreement using a person-centered approach (i.e., profile agreement):}

Although ASD and TD individuals tended to show similar levels of agreement for each trait, it is possible that they will disagree with informants about their trait profiles, i.e., which traits are more or less definitive of them. Table 6 shows agreement correlations between self- and parent-rated profiles, across the total sample and separately by group. We found higher overall agreement in the TD sample. However, decomposing overall agreement into its constituent parts of distinctive and normative agreement indicated that the higher agreement in the TD sample was driven by TD individuals' having higher normative agreement relative to the ASD sample, both in terms of participants' self-rated profiles' converging with the average self-rated profile and the parent-rated profiles' converging with the average parent-rated profile. An interesting implication of lower normative agreement in the ASD group relative to the TD group is that the ASD group was less homogenous than the TD group, with ASD targets' tending to have less "average" profiles. However, with regard to distinctive agreement, which is the more telling index of self-insight, ASD and TD samples did not differ from each other, suggesting that individuals with ASD and TD individuals have comparable self-insight.

Do ASD individuals self-enhance (vs. self-diminish) relative to TD individuals?: Finally, we examined directional deviations between child self- and parent-reported personality traits 
using $t$-tests. Consistent with our prediction, children with ASD tended to rate their personality traits more favorably than did their parents, rating themselves as more Conscientious $(d=+.83, p<.01)$, more Open to Experience $(d=+.44, p<.05)$, and less Neurotic $(d=-.89, p<.01)$ than their parents rated them; no significant differences were found for Agreeableness $(d=+.15, n s)$ or Extraversion $(d=+.27, n s)$, although they were in the direction of self-enhancement. The effect sizes for Conscientiousness and Neuroticism were large (Cohen, 1988), indicating a high degree of self-enhancement. In contrast, TD children tended to rate their personality traits in a less favorable manner than did their parents, indicating that they were less Agreeable $(d=-.70, p<.01)$, less Open to Experience $(d=-.32, p<.05)$, and more Neurotic $(d=+.43, p<.05)$ than their parents rated them; no significant differences were found for Conscientiousness $(d=-.27, n s)$ or Extraversion $(d=-.33, n s)$.

Thus, from a trait-centered approach, we found significant levels of self-other agreement for nearly all Big Five personality traits in individuals with ASD. Although these correlations were far from perfect, the level of agreement was comparable to that found in our TD individuals. We also found comparable levels of self-other agreement in the two groups using a person-centered approach - ASD and TD groups showed similar levels of distinctive agreement. Finally, individuals with ASD and TD individuals were characterized by tendencies to self-enhance and self-diminish, respectively. The implications of these and the previous findings are discussed below.

\section{General Discussion}

The present research investigated two broad questions about individuals with ASD: (1) Do their personality characteristics differ from those of TD individuals?, and (2) Do they have poor insight into these personality characteristics, both in terms of self-other agreement and directional deviations from informant reports?

\section{Personality in Autism}

With regard to the first question, Studies 1 and 2 demonstrated that children, adolescents, and young adults with ASD have distinct personality profiles as compared to TD individuals. As hypothesized, individuals with ASD tended to be higher in Neuroticism and lower in Extraversion, Agreeableness, Conscientiousness, and Openness to Experience. These personality differences (a) were observed in samples of children and adolescents as well as adults, (b) were perceived similarly by both self and parents, (c) were similar for males and females, and (d) held after controlling for IQ.

By examining personality in two age cohorts of ASD and TD individuals using the same Big Five measure, we were able to determine that personality is indeed affected in adults with ASD and to delineate a (very) preliminary and tentative understanding of personality trait development from late childhood to young adulthood in ASD. We found trait differences in young adults in Study 1 that were even greater in magnitude than those reported by children and adolescents in Study 2, indicating that personality differences are indeed evident in adults. This finding also presents the possibility that personality differences persist in adulthood and might even increase. More rigorous designs appropriate to these questions, 
such as longitudinal studies that track stability and change of personality in the same set of individuals with ASD over time, will be important to implement in the future. As Happé and Charlton (2012) observed, the first children ever identified as having "autism" since the term came into clinical use in the 1940s are just now entering old age. Nevertheless, the vast majority of research on autism has ventured no further than adolescence, leaving areas for research on adults with ASD wide open and critical to conduct.

The replication of findings across self and parent reports in Studies 1 and 2 strengthens the claim that these are actual personality differences and do not reflect the unique biases of a particular informant. Also, the inclusion of a sufficient number of girls and women in both ASD cohorts allowed us to determine that the personality traits associated with ASD did not differ for men and women (Study 1) or for boys and girls (Study 2), despite characterization of ASD as a fundamentally "male" syndrome (e.g., as per the "extreme male brain" theory of autism, Baron-Cohen, 2002). Indeed, due to the significantly higher rate of autism among boys, girls are often neglected in research on ASD. Thus, while not a primary aim of the present research, results provide much needed data on the interpersonal and intrapsychic manifestations of ASD in girls and women.

The current research has several implications for understanding the link between autism and personality. First, the findings provide a comprehensive portrait of the personality traits associated with ASD and align with De Pauw et al. (2011) and Kanai et al. (2011) to suggest that the unique attributes of individuals with ASD as manifested in their personality cut across all basic traits: rather than being restricted to the interpersonal domains of the Big Five - Extraversion and Agreeableness - individuals with ASD showed differences in all five domains. As a point of comparison, the alteration of personality in ASD is more extensive than that seen in attention deficit hyperactivity disorder, a condition that shares many characteristics with ASD and that is often comorbid with it, but for which Extraversion and Openness to Experience do not seem to be significantly affected (Nigg et al., 2002). The only possible exception in the breadth of personality difference was for Openness to Experience, the one dimension for which De Pauw et al. and Kanai et al. yielded divergent findings and, interestingly, the one dimension of the Big Five that is not consistently represented in proposed dimensional models of psychopathology (Saulsman \& Page, 2004; Widiger \& Simonsen, 2005).

The current findings also point to which personality traits in ASD are affected most. Effect sizes across Studies 1 and 2 suggest that Neuroticism and Conscientiousness, followed by Agreeableness, were the key areas of group difference. In contrast, De Pauw et al. (2011) pointed to Extraversion followed by Openness, and Kanai et al. (2011) to Neuroticism followed by Extraversion, as the main points of divergence. More work is needed to achieve a coherent understanding of which traits are central to defining ASD relative to normal development and to determine the source of disparity between studies (e.g., cultural moderators of actual vs. apparent differences, other sample characteristics, assessment methods).

Neuroticism was also the best predictor of group membership in the discriminant function analyses. Previous clinical studies have underscored the importance of Neuroticism in 
differentiating between clinical and non-clinical groups (Bagby, Costa, Widiger, Ryder, \& Marshall, 2005; Morey et al., 2002). As a trait that deals with emotional reactivity, lability, dysregulation, and overall distress, Neuroticism may well serve as a general marker for susceptibility to psychopathology. Especially when combined with low Conscientiousness, Neuroticism paves the way for it (Muris, 2006). The extent to which then "adding" low levels of Agreeableness and Extraversion results in features consistent with ASD in particular would be profitably explored by using the Big Five to compare ASD to other psychiatric disorders, not just to typically developing individuals. Pinpointing the areas of major impairment at the level of broad personality traits can help researchers appreciate some of the core vulnerabilities associated with ASD and highlight which aspects of functioning to monitor and target in treatment.

In studying ASD within the context of the Big Five, the current research contributes to a growing move toward conceptualizing typical and atypical functioning within a common framework - along a single set of continua. Researchers are currently shifting toward a dimensional trait model for refining the diagnostic system of the DSM (Adam, 2013; Cuthbert \& Insel, 2013; Krueger, Derringer, Markon, Watson, \& Skodol, 2011; Widiger \& Costa, 2012; Wright et al., in press). The proposed model comprises twenty-five maladaptive personality traits that fall within the five higher-order domains of negative affectivity (e.g., emotional lability, restricted affectivity), social detachment (e.g., withdrawal, intimacy avoidance), antagonism (e.g., manipulativeness, deceitfulness), disinhibition (e.g., impulsivity, rigid perfectionism), and psychoticism (e.g., unusual beliefs and experiences, perceptual dysregulation), all with varying correspondences to the Big Five. This formulation of maladaptive trait levels reflecting and undergirding pathology has tended to focus on personality disorders - themselves largely studied in the context of adulthood - but could be extended to other forms of psychopathology, such as earlyemerging developmental disorders like autism.

To be sure, the current studies produced at least three findings that call for caution in treating ASD as dimensional. First, the Big Five, despite offering a valuable taxonomy for describing the full range of personality variation, were far from perfect predictors of ASD vs. TD group membership according to discriminant function analyses, suggesting there is more to ASD than extreme personality trait levels. Second, personality traits explained a negligible portion of the variance in clinician-observed ASD-related behaviors in both of our ASD samples and did not predict variability in parent-rated ASD symptoms within the ASD or TD groups, not even when parents provided all information, in which case trait-symptom associations should have been inflated because of shared method variance. Third, we found disparate links between personality traits and adjustment problems (internalizing/ externalizing) in the ASD vs. TD groups, again arguing against continuity across groups. In the TD group, internalizing was related to Neuroticism and low Extraversion, and externalizing, to low Conscientiousness and low Agreeableness, replicating common findings on personality predictors of maladjustment in children (Prinzie et al., 2003; Van den Akker et al., 2013). However, Neuroticism and low Agreeableness - not low Extraversion - were related to Internalizing in ASD, and Neuroticism in addition to low 
Agreeableness and low Conscientiousness were related to externalizing in ASD, suggesting that traits have unique relationships with maladjustment in ASD.

In fact, we found a provocative relation between Neuroticism and ASD symptoms in Study 2 that suggests that this trait in the context of ASD, at least in adulthood, may operate differently than would be expected based on the normal personality literature. Neuroticism was negatively related to symptom severity in adults with ASD. That is, higher Neuroticism predicted lower symptoms. Although baffling at first blush, this association actually accords with previous work on ASD and depression. Vickerstaff et al. (2007) found that higher intellectual functioning in individuals with ASD predicted better social functioning but also greater depression because it was associated with greater awareness of social deficits and, thus, lower perceptions of social competence. Other investigators have explained higher rates of depression in higher functioning individuals with ASD in similar ways (Capps, Sigman, \& Yirmiya, 1995; Gillberg, 1984; Green, Gilchrist, Burton, \& Cox, 2000; Hill, Berthoz, \& Frith, 2004). ${ }^{5}$ Perhaps adults with ASD are even more likely to show better social functioning alongside greater distress due to their having had more opportunity to experience the discrepancy between their desired vs. actual behavior and outcomes. Future work should directly test the validity of this interpretation and replicate the tendency for more neurotic adults to show lower levels of ASD symptomatology, especially given the tenuousness of this finding when outliers are excluded.

To further probe the dimensionality of ASD, researchers should examine the personality correlates of ASD using a measure of the Big Five that is specifically designed to tap pathological functioning (e.g., the Personality Inventory for DSM-5; Krueger, Derringer, Markon, Watson, \& Skodol, 2012). Doing so might allow the five-factor model to explain more of the variance in ASD. For example, Openness, on which we found small group differences, is not the same as its pathology-focused analogue, psychoticism (also labeled schizotypy, oddity, or peculiarity), which contains considerable variation beyond that of typical everyday functioning and encompasses unusual experiences and beliefs, perceptual dysregulation, and eccentric thought (Krueger et al., 2011; Tackett, Silberschmidt, Krueger, \& Sponheim, 2008). In fact, psychoticism might be a dimension where autism especially makes its mark. There is now evidence suggesting that ASD and schizophrenia exist on the same genetically underpinned continuum, labeled "developmental brain dysfunction" (Moreno-De-Luca et al., 2013), making a dimension that represents aberrant basic perceptual and cognitive processing of reality important to assess in ASD.

Connections between personality and autism may also elucidate the considerable heterogeneity observed within the ASD phenotype. Even if personality did not predict variability in ASD symptom severity in the current research, it could be that personality relates to specific constellations of maladaptive characteristics in ASD. For example, Wing and Gould (1979) distinguished between three subtypes of autism - aloof, passive, and active-but-odd - that differ in characteristics such as the tendency to spontaneously

\footnotetext{
${ }^{5}$ Consistent with the idea that higher intellectual functioning is related to self-insight, we found that IQ in the ASD group was associated with distinctive agreement, $r=.30, p<.05$; this association was not significant in the TD group, $r=.14, n s$. However, inconsistent with the idea that higher self-insight is related to better social functioning, we found no significant associations between distinctive agreement and ASD symptom severity or internalizing/externalizing, either within or across the ASD and TD groups.
} 
approach others (evidenced only by the active-but-odd type) versus the tendency to amiably respond to others' approaches (evidenced by both the passive and active-but-odd types, but not the aloof type). These characteristics could relate to Big Five traits of Extraversion, Agreeableness, and Neuroticism. In addition, autism often co-occurs with personality disorders. Lugnegård, Hallerbäck, and Gillberg (2012) found that $48 \%$ of a sample of individuals with Asperger's syndrome met criteria for schizoid, avoidant, obsessivecompulsive, or schizotypal personality disorders, and remarked that ASD comorbid with schizoid personality disorder seemed to correspond to the "aloof" type from Wing's classification. Perhaps personality can help flag autism that runs alongside other conditions that have personality dysfunction at their heart. Assessing differential standing on the Big Five could thus facilitate a more nuanced characterization of autism and its myriad manifestations.

One question that cannot be answered by the present research is how to explain the link between personality and autism. Tackett (2006) described several non-mutually exclusive models that seem applicable in the present context. First, the spectrum model proposes that personality traits and psychopathology lie on a single continuum, with psychopathology being a more extreme manifestation of a particular trait or set of traits. Second, the vulnerability or predisposition model proposes that certain personality traits put children and adolescents at greater risk for developing a particular form of psychopathology. Third, the scar or complication model proposes that psychopathology changes, or influences the development of, personality traits. Fourth, the pathoplasty or exacerbation model proposes that personality traits shape the way psychopathology manifests, perhaps channeling the phenotypic expression of the underlying disorder into a subtype. Longitudinal studies, beginning early in development, are needed to test these different possibilities. In addition, it would be helpful to track the biological mechanisms common to personality traits and ASD. For example, the neuropeptide oxytocin, which appears to play a critical role in the formation and maintenance of social behavior from infancy onward with implications for Agreeableness, may be deficient and part of an underdeveloped system in autism (Carter, 2007).

Finally, by situating autism within the Big Five framework, we can link the condition to all other psychological constructs and outcomes that have been related to the Big Five. Research has indicated that all five dimensions (i.e., for the most part, higher Extraversion, Agreeable-ness, Conscientiousness, Openness, and lower Neuroticism) are associated with successful life outcomes, and that opposite standing on these dimensions contributes to problematic outcomes (Mullins-Sweatt \& Widiger, 2010; Ozer \& Benet-Martinez, 2006). Indeed, a latent class analysis conducted by De Clercq, Rettew, Althoff, and de Bolle (2012) found that this same trait profile we found for ASD individuals - that is, of systematically lower trait levels relative to the modal personality profile - represented the most "vulnerable" personality profile, with the highest associations with various forms of psychopathology (but not including ASD). Based on their Big Five personality profile, individuals with ASD are more likely to have poor performance at school and work; less satisfying and less stable romantic relationships; less social acceptance; less social support; lower subjective well-being and more distress; and to experience more health problems and 
shorter lifespans (Ozer \& Benet-Martinez, 2006). Many of these outcomes have, in fact, been documented in individuals with ASD, and the present findings suggest that we can turn to personality as one explanatory mechanism.

\section{Self-Insight in Autism}

The current research contributes to abiding questions about whether individuals with autism have self-insight. Despite a widespread and longstanding assumption that they do not, we found individuals with ASD showed significant levels of understanding into their personality across different operationalizations of self-insight. Using a trait-centered approach, ASD individuals showed significant self-other agreement for four of the Big Five dimensions. Although these correlations were far from perfect, the level of agreement was similar to that in the TD individuals. Using a person-centered approach, ASD and TD individuals showed similar distinctive agreement, that is, agreement on their unique profile of defining traits. These findings suggest that individuals with ASD have a reasonable degree of insight into their own personalities. They recognize, at least to some extent, that they tend to be socially withdrawn and inhibited; less soft-hearted, empathic, and warm; less organized and responsible; and less emotionally stable, with more frequent and intense bouts of anxiety and sadness, than TD individuals. They also recognize, at least to some extent, the differential extent to which these qualities define them.

Agreement in the ASD group was highest for Neuroticism. Neuroticism is the personality dimension that, perhaps as a function of dealing extensively with negative affective states, most set apart ASD and TD individuals according to mean-level group differences and discriminant function analyses in both studies. Finding high self-other agreement in the ASD group for this domain relative to the others is noteworthy as well as counterintuitive given that alexithymia is fairly common in individuals with ASD (Ben Shalom et al., 2006; Berthoz \& Hill, 2005; Hill, Berthoz, \& Frith, 2004) and given that Neuroticism usually elicits the lowest level of self-other agreement in TD individuals - as it did in our TD sample - partly because its indicators are less observable to informants (John \& Robins, 1993; Funder, 1999).

It could be that the high levels of Neuroticism in individuals with ASD made aspects of this dimension sufficiently salient to the individuals and observable to others to allow for high agreement. Consistent with this, Furr, Dougherty, Marsh, \& Mathias (2007) found across a sample of children with and without conduct disorder that self-other agreement was higher for traits central to the pathology than for those less relevant. It could also be that children with ASD are encouraged to talk about their thoughts and feelings, particularly those dealing with anxiety and upset, as those are a major issue for them and may be explicitly confronted with parents, teachers, and therapists, promoting higher agreement. Consistent with this, studies examining whether ASD individuals have insight into their specific psychiatric symptoms - termed "clinical insight" (Beck et al., 2004) - as well as life difficulties stemming from them, such as academic and physical problems, suggest moderately high self-other agreement (median $r=.45$ ), although with a very broad range of results across studies (range $=-.08$ to .73 ) (Farrugia $\&$ Hudson, 2006; Johnson et al., 2009; Knott et al., 2006; Koning et al., 2001; Vickerstaff et al., 2007). 
However, there was one personality dimension - Extraversion - for which self-other agreement was significantly lower in the ASD group relative to the TD group, a difference in part attributable to the superior self-insight of TD individuals for this dimension above all others, itself a common finding in the personality judgment literature due to its high observability (e.g., John \& Robins, 1993; Funder, 1999). Given that self-reported Extraversion in children with ASD was not systematically biased relative to parent reports, the lower agreement suggests a greater amount of "noise" (i.e., random error) in the selfperception of individuals with ASD for this dimension. One possibility is that individuals with ASD used more transient reference points when gauging their level of Extraversion, perhaps basing their reports on their latest social interaction; that is, the "noise" could be attributed to state effects. Another possibility is that some children with ASD compare themselves to others with ASD, leading to an overestimation of their Extraversion level, whereas others compare themselves to TD individuals, leading to a more accurate (or perhaps even underestimation) of their Extraversion level; such individual differences would attenuate the magnitude of child-parent agreement. Finally, because individuals with ASD have selectively social deficits, some individuals could have had difficulty understanding the questions that probed Extraversion. This lack of Expertise (Funder, 1995) could also explain why self-other agreement for Conscientiousness in ASD was so low that it failed to reach significance.

Overall, finding a significant level of self-insight in ASD prompts a host of intriguing questions. For example, what is the process by which individuals with ASD are able to know themselves? The items on the BFI would have called for individuals' being familiar not only with their internal states (e.g., "is depressed, blue") but also their social proclivities (e.g., "is helpful and unselfish with others"), relative mental aptitudes (e.g., "is ingenious, a deep thinker"), and even how they are perceived by and/or affect others (e.g., "generates a lot of enthusiasm"). Relatedly, what does the success of individuals with ASD with selfdescription say about the three pathways that we distinguished in the literature for how selfknowledge can break down or be preempted in ASD? The present findings suggest that individuals with ASD have sufficient introspective capacity, sufficient mastery of concepts for tracking their personal attributes (such that they can recognize and use these concepts), and may even have sufficient experience with and understanding of the social world to learn about their personality traits and how they come across to others, at least to their parents. As mentioned, it could be that individuals with ASD get a generous amount of explicit feedback about themselves due to their condition. More research is needed to determine the possible sources of self-knowledge in ASD. For example, research can utilize measures of selfconsciousness and self-reflection, inner speech, social comparison, Theory of Mind and other processes for understanding implicit social feedback, quantity and quality of available explicit social feedback and performance information, and size and composition of social networks, to determine whether, and to what extent, they mediate accurate self-knowledge in ASD.

Indeed, given our findings, it is interesting that even individuals with ASD themselves do not think they know themselves well. Adults with ASD do not believe they have any more insight into their inner states and personal traits than close others have about them, whereas non-clinical controls consider themselves the "self”-experts (Mitchell \& O'Keefe, 2008). 
Similarly, Dritschel, Wisely, Goddard, Robinson, \& Howlin (2010) found that adolescents with ASD believe that close others have more knowledge about their internal states and qualities than they do. This is remarkable, given that most people take for granted that they know themselves better than others know them, even for attributes for which this is not the case (Vazire, 2010). One intriguing possibility is that trait self-knowledge is preserved in the face of other disturbances in self-perception. Instances like this have been documented by Klein and his colleagues for several disorders, most recently for schizophrenia (Klein, Altinyazar, \& Metz, in press). Their work has led them to suggest that self-knowledge "is impervious to a host of cognitive and neuropsychological insults capable of rendering other systems of knowledge partially or fully inoperable" and that trait self-knowledge may be "an unusually robust, evolutionarily ancient social adaptation" (p. 4).

In addition to assessing self-insight in terms of agreement, we also examined the tendency for ASD and TD individuals to show systematic directional deviations (self-enhancement vs. self-diminishment) in their personality trait ratings. The ASD group tended to provide overly favorable reports of their personality, whereas the TD group tended to provide unfavorable reports, relative to parent reports. Here, questions arise as to the underlying reasons for selfenhancement in individuals with ASD. Notably, self-enhancement is not an uncommon phenomenon. Research with TD individuals has found that "[m]ost people, most of the time, see themselves through rose-colored glasses" (Sedikides, Horton, \& Gregg, 2007, p. 783).

Studies comparing self-evaluations to an external criterion have generally found a small self-enhancement effect -- typically around a third of a standard deviation (e.g., John \& Robins, 1994; 1997) -- that reflects the presence of substantial individual differences in the degree and direction of bias. In the present research, self-enhancement was found only in the ASD sample, with effect sizes surpassing .80 standard deviations for Conscientiousness and Neuroticism. Whereas cognitive and motivational factors have been invoked to explain selfenhancement in TD individuals (Schriber \& Robins, 2012), it is not clear that the same processes account for self-enhancement in individuals with ASD. For example, in TD individuals, narcissism is strongly associated with the tendency to self-enhance (e.g., John \& Robins, 1994). Could it be that individuals with ASD are more narcissistic than TD individuals?

Without using the term "narcissistic," Attwood (2007) suggested that individuals with ASD, especially those with superior intellectual abilities, (1) may overcompensate for feelings of inadequacy in social situations by becoming "arrogant and egocentric" (p. 20); (2) "have considerable difficulty acknowledging that they have made a mistake... can be hypersensitive to any suggestion of criticism, yet overly critical of others, including teachers, parents or authority figures" (p. 21); and (3) turn "a lack of ability in social play with peers and in interactions with adults [into] behaviors to achieve dominance and control" (p. 26). Frith and colleagues similarly call attention to a certain self-absorption intrinsic to ASD, terming it naïve egocentrism (Frith \& de Vignemont, 2005). When the low Agreeableness that characterizes individuals with ASD is thrown into the mix, these individuals might have the makings of a narcissist. However, no studies to date have examined a link between autism and narcissism. Only one exploratory study, Abell and Hare (2005), nods at the issue with observations of elevated levels of grandiose and persecutory 
delusions in a sample of adult males with Asperger's. Thus, evaluating narcissism in ASD in future studies could be one way to unpack the positivity bias seen in the present research.

Another issue raised by the current findings is whether the parents themselves - the measure of the "truth" - are differentially biased toward ASD vs. TD children. For example, the positive biases seen in the ASD sample could actually reflect excessive harshness on the part of the parents, rather than the overly rosy self-views of individuals with ASD. Years of learning about and living with a child with ASD might lead parents to be more knowledgeable of, observant of, and acutely sensitive to autism-related traits and other perceived shortcomings in their children. As such, the parents of individuals with ASD might be liable to assign ratings that are excessively unfavorable, their failing to see their children with dispassionate eyes when considering their attributes. Following this reasoning, it is possible that in Study 2, the difference in Openness to Experience, which only held for the parent reports, reflects the unique perspective of parents toward their children with ASD, rather than an actual tendency for children and adolescents with ASD to be less exploratory, imaginative, and creative than TD children and adolescents. Ultimately, to assuage the concern of observer harshness and to further investigate self-criterion agreement and positive bias in ASD, future work should introduce other criterion measures, such as objective behavioral measures and ratings along the trait parameters by observant yet less emotionally involved informants (e.g., clinicians).

Taken together, the present findings provide evidence that individuals with autism have distinct personality traits and a reasonable degree of insight into their relative standing on these traits, with a tendency to provide systematically overly favorable ratings of themselves. A better understanding of the personality and self-evaluative processes in individuals with ASD could have important ramifications for how to conceptualize and treat autism, as well as for how to understand the interface between personality, self-insight, and pathological functioning more generally. We may ask, for example, what is the relation between personality, self-insight, and the potential for personality change in autism? Also, is self-insight in autism associated with better outcomes for individuals with ASD either intrapsychically (e.g., subjective well-being) or interpersonally (e.g., social functioning) or both? We hope our findings pave the way for more research on personality traits in individuals with ASD and on the nature and extent of their insight into these and other aspects of themselves.

\section{Acknowledgments}

This research was supported by National Institute of Child Health and Human Development Grant HD064687 to Roberta A. Schriber, National Institute on Drug Abuse Grant DA017902 to Richard W. Robins, and National Institute of Mental Health Award 1-K-08 MH074967-01 and Building Interdisciplinary Research Careers in Women's Health Award K12 HD051958 funded by the National Institute of Child Health and Human Development, Office of Research on Women's Health, Office of Dietary Supplements, and National Institute of Aging to Marjorie Solomon.

\section{References}

Abell R, Hare DJ. An experimental investigation of the phenomenology of delusional beliefs in people with Asperger syndrome. Autism: The International Journal of Research and Practice. 2005; 9:515531. [PubMed: 16287703] 
Adam D. Mental health: On the spectrum. Nature. 2013; 496:416. [PubMed: 23619674]

Akshoomoff N, Lord C, Lincoln AJ, Courchesne RY, Carper RA, Townsend J, Courchesne E. Outcome classification of preschool children with autism spectrum disorders using MRI brain measures. Journal of American Academy of Child and Adolescent Psychiatry. 2004; 43:349-357.

American Psychiatric Association. Diagnostic and statistical manual of mental disorders. Revised 4th. Washington, DC: Author; 2000.

Assaf M, Jagannathan K, Calhoun VD, Miller L, Stevens MC, Sahl R, O'Boyle JG, Schultz RT, Pearlson GD. Abnormal functional connectivity of default mode sub-networks in autism spectrum disorders. NeuroImage. 2010; 53:247-256. [PubMed: 20621638]

Asperger H. Die “Autistischen Psychopathen” im Kindesalter. Archiv fur Psychiatrie und Nervenkrankheiten. 1944; 117:76-136.

Attwood, T. Asperger's syndrome: A guide for parents and professionals. London: Jessica Kingsley; 2007.

Bagby RM, Costa PT, Widiger TA, Ryder AG, Marshall M. DSM-IV personality disorders and the five-factor model of personality: A multi-method examination of domain and facet-level predictions. European Journal of Personality. 2005; 19:307-324.

Baron-Cohen, S. Mindblindness: An essay on autism and theory of mind. MIT Press/Bradford; Books: 1995.

Baron-Cohen S. The extreme male brain theory of autism. Trends in Cognitive Sciences. 2002; 6:248254. [PubMed: 12039606]

Baron-Cohen, S. The essential difference: Men, women and the extreme male brain. London: Penguin Books; 2003.

Baron-Cohen, S. Autism: The empathizing-systemizing (E-S) theory. In: Miller, M., editor. The Year in Cognitive Neuroscience. Vol. 1156. Annals of the New York Academy of Science; 2009. p. 68-80.

Bastiaansen L, Rossi G, Schotte C, De Fruyt G. The structure of personality disorders: Comparing the DSM-IV-TR axis II classification with the five-factor model framework using structural equation modeling. Journal of Personality Disorders. 2011; 25:378-396. [PubMed: 21699398]

Bauminger N, Shulman C, Agam G. Peer interaction and loneliness in high-functioning children with autism. Journal of Autism and Developmental Disorders. 2003; 33:489-507. [PubMed: 14594329]

Beck AT, Baruch E, Balter JM, Steer RA, Warman DM. A new instrument for measuring insight: The Beck Cognitive Insight Scale. Schizophrenia Research. 2004; 68:319-330. [PubMed: 15099613]

Ben Shalom D, Mostofsky SH, Hazlett RL, Goldberg MC, Landa RJ, Faran Y, et al. Normal physiological emotions but differences in expression of conscious feelings in children with highfunctioning autism. Journal of Autism and Developmental Disorders. 2006; 36:395-400. [PubMed: 16565884]

Berthoz S, Hill EL. The validity of using self-reports to assess emotion regulation abilities in adults with autism spectrum disorder. European Psychiatry. 2005; 20:291-298. [PubMed: 15935431]

Berument SK, Rutter M, Lord C, Pickles A, Bailey A. Autism screening questionnaire: Diagnostic validity. The British Journal of Psychiatry. 1999; 175:444-451. [PubMed: 10789276]

Borthwick L. Adulthood: Life lessons. Nature. 2012; 491:S10-S11. [PubMed: 23136653]

Capps L, Kasari C, Yirmiya N, Sigman M. Parental perception of emotional expressiveness in children with autism. Journal of Consulting and Clinical Psychology. 1993; 61:475-484. [PubMed: 8326050]

Carruthers, P. Language, thoughts and consciousness An essay in philosophical psychology. Cambridge: Cambridge University Press; 1996.

Carter CS. Sex differences in oxytocin and vasopressin: Implications for autism spectrum disorders? Behavioural Brain Research. 2007; 176:170-186. [PubMed: 17000015]

Chevallier C, Kohls G, Troiani V, Brodkin ES, Schultz RT. The social motivation theory of autism. Trends in Cognitive Sciences. 2012; 16:231-239. [PubMed: 22425667]

Cohen, J. Statistical power analysis for the behavioral sciences. 2nd. Hillsdale, NJ: Erlbaum; 1988.

Colvin RC. "Judgeable" people: Personality, behavior, and competing explanations. Journal of Personality and Social Psychology. 1993; 64:861-873. [PubMed: 8505714] 
Cooley, CH. Human nature and the social order. New York: Scribner; 1902.

Costa, PT.; McCrae, RR. Revised NEO Personality Inventory (NEO PI-R) and NEO Five-Factor Inventory (NEO-FFI) professional manual. Odessa, FL: Psychological Assessment Resources; 1992.

Cuthbert BN, Insel TR. Toward the future of psychiatric diagnosis: The seven pillars of RDoC. BMC Medicine. 2013; 11:126. [PubMed: 23672542]

Dawson G, Toth K, Abbott R, Osterling J, Munson J, Estes A, Liaw J. Early social attention impairments in autism: Social orienting, joint attention, and attention to distress. Developmental Psychology. 2004; 40:271-283. [PubMed: 14979766]

Dawson G, Webb S, Schellenberg GD, Dager S, Friedman S, Aylward E, et al. Defining the broader phenotype of autism: Genetic, brain, and behavioral perspectives. Development and Psychopathology. 2002; 14:581-611. [PubMed: 12349875]

De Pauw SSW, Mervielde I, Van Leeuwen KG, De Clercq BJ. How temperament and personality contribute to the maladjustment of children with autism. Journal of Autism and Developmental Disorders. 2011; 41:196-212. [PubMed: 20526733]

Di Martino A, Ross K, Uddin LQ, Sklar AB, Castellanos FX, Milham MP. Functional brain correlates of social and nonsocial processes in autism spectrum disorders: An activation likelihood estimation meta-analysis. Biological Psychiatry. 2009; 65:63-74. [PubMed: 18996505]

Domínguez LG, Velázquez JLP, Galán RF. A model of functional brain connectivity and background noise as a biomarker for cognitive phenotypes: Application to autism. PLoS ONE. 2013; 8:e61493. [PubMed: 23613864]

Dritschel B, Wisely M, Goddard L, Robinson S, Howlin P. Judgements of self-understanding in adolescents with Asperger syndrome. Autism: The International Journal of Research and Practice. 2010; 14:509-518. [PubMed: 20841342]

Duffy FH, Als H. A stable pattern of EEG spectral coherence distinguishes children with autism from neuro-typical controls - a large case control study. BMC Medicine. 2012; 10:64. [PubMed: 22730909]

Farrugia S, Hudson J. Anxiety in adolescents with Asperger syndrome: Negative thoughts, behavioural problems and life interference. Focus on Autism and Other Developmental Disabilities. 2006; 21:25-35.

Fein D, Pennington B, Markowitz P, Braverman M, Waterhouse L. Towards a neuropsychological model of infantile autism: Are the social deficits primary? Journal of the American Academy of Child Psychiatry. 1986; 25:198-212. [PubMed: 3700907]

Fombonne E. Epidemiological surveys of autism and other pervasive developmental disorders: An update. Journal of Autism and Developmental Disorders. 2003; 33:365-382. [PubMed: 12959416]

Frith U, de Vignemont F. Egocentrism, allocentrism and Asperger syndrome. Consciousness and Cognition. 2005; 14:719-38. [PubMed: 15996486]

Frith U, Happé F. Theory of mind and self-consciousness: What is it like to be autistic? Mind \& Language. 1999; 14:1-22.

Funder DC. On the accuracy of personality judgment: A realistic approach. Psychological Review. 1995; 102:652-670. [PubMed: 7480467]

Funder, DC. Personality judgment: A realistic approach to person perception. San Diego, CA: Academic Press; 1999.

Furr RM. The double-entry intraclass correlation as an index of profile similarity, meaning, limitations, and alternatives. Journal of Personality Assessment. 2010; 92:37-41.

Furr RM, Dougherty DM, Marsh DM, Mathias CW. Personality judgment and personality pathology: Self-other agreement in adolescents with conduct disorder. Journal of Personality. 2007; 75:629662. [PubMed: 17489894]

Gillberg C. Autistic children growing up: Problems during puberty and adolescence. Developmental Medicine and Child Neurology. 1984; 26:122-129. [PubMed: 6230277]

Green J, Gilchrist A, Burton D, Cox A. Social and psychiatric functioning in adolescents with Asperger syndrome compared with conduct disorder. Journal of Autism and Developmental Disorders. 2000; 30:279-293. [PubMed: 11039855] 
Happé F, Charlton RA. Aging in autism spectrum disorders: A mini-review. Gerontology. 2012; 58:70-78. [PubMed: 21865667]

Harter, S. Developmental perspective on the self system. In: Hetherington, EM., editor. Handbook of Child Psychology: Socialization, Personality, and Social Development. Wiley; New York: 1983. p. 257-386.

Haslam N, Holland E, Kuppens P. Categories versus dimensions in personality and psychopathology: A quantitative review of taxometric research. Psychological Medicine. 2012; 42:903-920. [PubMed: 21939592]

Hill EL. Executive dysfunction in autism. Trends in Cognitive Sciences. 2004; 8:26-32. [PubMed: 14697400]

Hill EL, Berthoz S, Frith U. Brief report: Cognitive processing of own emotions in individuals with autistic spectrum disorder and in their relatives. Journal of Autism and Developmental Disorders. 2004; 34:229-235. [PubMed: 15162941]

Hobson, RP. Autism and the development of mind. Lawrence Erlbaum Associates; 1993.

Hobson, RP. The cradle of thought. London: Macmillan; 2002.

Hobson RP, Lee A, Hobson JA. Only connect? Communication, identification, and autism. Social Neuroscience. 2007; 2:320-335. [PubMed: 18633821]

Interagency Autism Coordinating Committee. Strategic plan for autism spectrum disorder research. 2010 NIH Publication No. 2010-7573.

Izuma K, Matsumoto K, Camerer CF, Adolphs R. Insensitivity to social reputation in autism. Proceedings of the National Academy of Sciences. 2011; 108:17302-17307.

John, OP.; Naumann, LP.; Soto, CJ. Paradigm shift to the integrative Big Five trait taxonomy: History, measurement, and conceptual issues. In: John, OP.; Robins, RW.; Pervin, LA., editors. Handbook of Personality: Theory and Research. 3rd. New York: The Guilford Press; 2008. p. 114-158.

John OP, Robins RW. Determinants of interjudge agreement on personality traits: The Big Five domains, observability, evaluativeness, and the unique perspective of the self. Journal of Personality. 1993; 41:521-551. [PubMed: 8151500]

John OP, Robins RW. Accuracy and bias in self-perception: Individual differences in selfenhancement and the role of narcissism. Journal of Personality and Social Psychology. 1994; 66:206-219. [PubMed: 8126650]

John OP, Robins RW. Effects of visual perspective and narcissism on self-perception: Is seeing believing? Psychological Science. 1997; 8:37-42.

Johnson SA, Filliter JA, Murphy RR. Discrepancies between self- and parent-perceptions of autistic traits and empathy in high functioning children and adolescents on the autism spectrum. Journal of Autism and Developmental Disorders. 2009; 39:1706-1714. [PubMed: 19626433]

Kanai C, Iwanami A, Hashimoto R, Ota H, Tani M, Yamada T, Kato N. Clinical characterization of adults with Asperger's syndrome assessed by self-report questionnaires based on depression, anxiety, and personality. Research in Autism Spectrum Disorders. 2011; 5:1451-1458.

Kanner L. Autistic disturbances of affective contact. Nervous Child. 1943; 2:217-250.

Klein SB, Altinyazar V, Metz MA. Facets of self in schizophrenia: The reliability and accuracy of trait self-knowledge. Clinical Psychological Science. in press.

Knott F, Dunlop AW, Mackay T. Living with ASD. Autism. 2006; 10:609-617. [PubMed: 17088276]

Koning C, Magill-Evans J. Social and language skills in adolescent boys with Asperger syndrome. Autism. 2001; 5:23-36. [PubMed: 11708387]

Krueger RF, Derringer J, Markon KE, Watson D, Skodol AE. Initial construction of a maladaptive personality trait model and inventory for DSM-5. Psychological Medicine. 2012; 42:1879-1890. [PubMed: 22153017]

Krueger RF, Eaton NR, Derringer J, Markon KE, Watson D, Skodol AE. Personality in DSM-5: Helping delineate personality disorder content and framing metastructure. Journal of Personality Assessment. 2011; 93:325-331. [PubMed: 22804671]

Leslie AM, Thaiss L. Domain specificity in conceptual development: Neuropsychological evidence from autism. Cognition. 1992; 43:225-251. [PubMed: 1643814] 
Lombardo MV, Baron-Cohen S. The role of the self in mindblindness in autism. Consciousness and Cognition: An International Journal. 2011; 20:130-140.

Lombardo MV, Chakrabarti B, Bullmore ET, Wheelright SJ, Sadek SA, Suckling J, et al. Shared neural circuits for mentalizing about the self and others. Journal of Cognitive Neuroscience. 2010; 22:1623-1635. [PubMed: 19580380]

Lord C, Risi S, Lambrecht L, Cook EH Jr, Leventhal BL, DiLavore PC, Pickles A, Rutter M. The autism diagnostic observation schedule-generic: A standard measure of social and communication deficits associated with the spectrum of autism. Journal of Autism and Developmental Disorders. 2000; 30:205-223. [PubMed: 11055457]

Lord C, Rutter M, Le Couteur A. Autism Diagnostic Interview - Revised: A revised version of a diagnostic interview for carers of individuals with possible pervasive developmental disorders. Journal of Autism and Developmental Disorders. 1994; 24:659-685. [PubMed: 7814313]

Lugnegård T, Hallerbäck MU, Gillberg C. Psychiatric comorbidity in young adults with a clinical diagnosis of Asperger syndrome. Research in Developmental Disabilities. 2011; 32:1910-1917. [PubMed: 21515028]

Makrygianni MK, Reed P. A meta-analytic review of the effectiveness of behavioural early intervention programs for children with Autistic Spectrum Disorders. Research in Autism Spectrum Disorders. 2010; 4:577-593.

Matson JL, Worley JA, Kozlowski AM, Chung KM, Jung W, Yang JW. Cross-cultural differences of parent-reported social skills in children with autistic disorder: An examination between South Korea and the United States of America. Research in Autism Spectrum Disorder. 2012; 6:971977.

Mead, GH. Mind, self and society. Chicago: University of Chicago Press; 1934.

Meehl PE. Factors and taxa, traits and types, differences of degree and differences in kind. Journal of Personality. 1992; 60:117-174.

Mervielde I, De Clercq B, De Fruyt F, Van Leeuwen K. Temperament, personality, and developmental psychopathology as childhood antecedents of personality disorders. Journal of Personality Disorders. 2005; 19:171-201. [PubMed: 15899715]

Mervielde, I.; De Fruyt, F. Assessing children's traits with the Hierarchical Personality Inventory for Children. In: De Raad, B.; Perugini, M., editors. Big five assessment. Bern, Switzerland: Hogrefe \& Huber; 2002. p. 129-146.

Mitchell P, O'Keefe K. Do individuals with autism spectrum disorders think they know their own minds? Journal of Autism and Developmental Disorders. 2008; 38:1591-1597. [PubMed: 18311515]

Moreno-De-Luca A, Myers SM, Challman TD, Moreno-De-Luca D, Evans DW, Ledbetter DH. Developmental brain dysfunction: Revival and expansion of old concepts based on new genetic evidence. The Lancet Neurology. 2013; 12:406-414.

Morey LC, Gunderson JG, Quigley BD, Shea MT, Skodol AE, McGlashan TH, Stout RL, Zanarini MC. The representation of borderline, avoidant, obsessive-compulsive, and schizotypal personality disorders by the five-factor model. Journal of Personality Disorders. 2002; 16:215-234. [PubMed: 12136679]

Morin A. Self-awareness part 1: Definition, measures, effects, functions, and antecedents. Social and Personality Psychology Compass. 2011; 5:807-823.

Mullins-Sweatt SN, Widiger TA. Personality-related problems in living. Personality Disorders: Theory, Research, and Treatment. 2010; 1:230-238.

Mundy P, Gwaltney M, Henderson H. Self-referenced processing, neurodevelopment and joint attention in autism. Autism. 2010; 14:408-429. [PubMed: 20926457]

Muris P. Unique and interactive effects of neuroticism and effortful control on psychopathological symptoms in non-clinical adolescents. Personality and Individual Differences. 2006; 40:1409_ 1419.

Nigg JT, John OP, Blaskey LG, Huang-Pollock CL, Willcutt EG, Hinshaw SP, Pennington B. Big five dimensions and ADHD symptoms: Links between personality traits and clinical symptoms. Journal of Personality and Social Psychology. 2002; 83:451-469. [PubMed: 12150240] 
Norbury CF, Sparks A. Difference or disorder? Cultural issues in understanding neurodevelopmental disorders. Developmental Psychology. 2013; 49:45-58. [PubMed: 22390668]

Ozer DJ, Benet-Martínez V. Personality and the prediction of consequential outcomes. Annual Review of Psychology. 2006; 57:401-421.

Ozonoff, S.; Griffith, EM. Neuropsychological function and external validity of Asperger syndrome. In: Klin, A.; Volkmar, FR.; Sparrow, SS., editors. Asperger Syndrome. New York: Guilford Press; 2000. p. 72-96.

Paulhus, DL.; Vazire, S. The self-report method. In: Robins, RW.; Fraley, RC.; Krueger, R., editors. Handbook of Research Methods in Personality Psychology. New York: Guilford Press; 2007. p. 224-239.

Perner, J. Understanding the representational mind. Cambridge MA: MIT Press; 1991.

Perner J, Frith U, Leslie AM, Leekam SR. Exploration of the autistic child's theory of mind: Knowledge, belief and communication. Child Development. 1989; 60:689-700.

Piven J, Palmer P, Jacobi D, Childress D, Arndt S. Broader autism phenotype: Evidence from a family history study of multiple-incidence autism families. The American Journal of Psychiatry. 1997; 154:185-190. [PubMed: 9016266]

Prinzie P, Onghena P, Hellinckx W, Grietens H, Ghesquiére P, Colpin H. The additive and interactive effects of parenting and children's personality on externalizing behavior. European Journal of Personality. 2003; 17:95-117.

Raffman D. What autism may tell us about self-awareness: A commentary on Frith and Happé. Theory of Mind and Self Consciousness: What is It Like to Be Autistic? Mind \& Language. 1999; 14:2331.

Reynolds, CR.; Kamphaus, RW. BASC-2: Behavior assessment system for children, second edition manual. Circle Pines, MN: American Guidance Service; 2004.

Roberts BW, Kuncel NR, Shiner R, Caspi A, Goldberg LR. The power of personality: The comparative predictive validity of personality traits, socioeconomic status, and cognitive ability for predicting important life outcomes. Perspectives on Psychological Science. 2007; 2:313-345.

Rogers S. Interventions that facilitate socialization in children with autism. Journal of Autism and Developmental Disorders. 2000; 30:399-408. [PubMed: 11098875]

Rutter M. Concepts of autism: A review of research. Journal of Child Psychology and Psychiatry. 1968; 9:1-25. [PubMed: 4892153]

Rutter, M.; Bailey, A.; Lord, C. SCQ: The Social Communication Questionnaire. Western Psychological Services; Los Angeles, CA: 2003. Manual

Saulsman LM, Page AC. The five-factor model and personality disorder empirical literature: A metaanalytic review. Clinical Psychology Review. 2004; 23:1055-1085. [PubMed: 14729423]

Schrauger BR, Schoeneman TJ. Symbolic interactionist view of self: Through the looking glass darkly. Psychological Bulletin. 1979; 86:549-573.

Schriber, RA.; Robins, RW. Self-Knowledge: An individual-differences perspective. In: Vazire, S.; Wilson, TD., editors. Handbook of Self-Knowledge. New York City, NY: Guilford; 2012. p. 105-128.

Sedikides C, Horton RS, Gregg AP. The why's the limit: Curtailing self- enhancement with explanatory introspection. Journal of Personality. 2007; 75:783-824. [PubMed: 17576359]

Seltzer MM, Shattuck P, Abbeduto L, Greenberg JS. Trajectory of development in adolescents and adults with autism. Mental retardation and developmental disabilities research reviews. 2004; 10:234-247. [PubMed: 15666341]

Sipes M, Furniss F, Matson JL, Hattier M. A multinational study examining the cross cultural differences in social skills of children with autism spectrum disorders: A comparison between the United Kingdom and the United States of America. Journal of Developmental and Physical Disabilities. 2012; 24:145-154.

Solomon M, Ozonoff SJ, Cummings N, Carter CS. Cognitive control in autism spectrum disorders. International Journal of Developmental Neuroscience. 2008; 26:239-247. [PubMed: 18093787]

Solomon M, Ozonoff SJ, Ursu S, Ravizza S, Cummings N, Ly S, Cameron CS. The neural substrates of cognitive control deficits in autism spectrum disorders. Neuropsychologia. 2009; 47:25152526. [PubMed: 19410583] 
Soto CJ, John OP, Gosling SD, Potter J. The developmental psychometrics of Big Five self-reports: Acquiescence, factor structure, coherence, and differentiation from ages 10 to 20. Journal of Personality and Social Psychology. 2008; 94:718-737. [PubMed: 18361680]

Swedo, S. Research update: Autism in the DSM-V. IACC; Washington, DC: 2010.

Tackett JL. Evaluating models of the personality-psychopathology relationship in children and adolescents. Clinical Psychology Review. 2006; 26:584-599. [PubMed: 16820251]

Tackett JL, Silberschmidt AL, Krueger RF, Sponheim SR. A dimensional model of personality disorder: Incorporating DSM Cluster A characteristics. Journal of Abnormal Psychology. 2008; 117:454-459. [PubMed: 18489222]

Trapnell PD, Campbell JC. Private self-consciousness and the five-factor model of personality: Distinguishing rumination from reflection. Journal of Personality and Social Psychology. 1999; 76:284-304. [PubMed: 10074710]

Umeda S, Mimura M, Kato M. Acquired personality traits of autism following damage to the medial prefrontal cortex. Social Neuroscience. 2010; 5:19-29. [PubMed: 19637100]

Van den Akker AL, Deković M, Asscher JJ, Shiner RL, Prinzie P. Personality types in childhood: Relations to latent trajectory classes of problem behavior and overreactive parenting across the transition into adolescence. Journal of Personality and Social Psychology. 2012; 104:750-764. [PubMed: 23276273]

Vazire S. Who knows what about a person? The Self-Other Knowledge Asymmetry (SOKA) model. Journal of Personality and Social Psychology. 2010; 98:281-300. [PubMed: 20085401]

Vickerstaff S, Heriot S, Wong M, Lopes A, Dossetor D. Intellectual ability, self-perceived social competence, and depressive symptomatology in children with high-functioning autistic spectrum disorders. Journal of Autism and Developmental Disorders. 2007; 37:1647-1664. [PubMed: 17146703]

Volkmar, FR.; Klin, A. Asperger's syndrome. Klin, A.; Volkmar, F.; Sparrow, SS., editors. Guilford; New York: 2000. p. 25-71.2000

Wechsler, D. Wechsler Abbreviated Scale of Intelligence (WASI). San Antonio, TX: Harcourt Assessment; 1999.

White SW, Oswald D, Ollendick T, Scahill L. Anxiety in children with autism spectrum disorders. Clinical Psychology Review. 2009; 29:216-229. [PubMed: 19223098]

Widiger, TA.; Costa, PT., Jr, editors. Personality disorders and the five-factor model of personality. 3rd. Washington, DC: American Psychological Association; 2012.

Widiger TA, Simonsen E. Alternative dimensional models of personality disorder: Finding a common ground. Journal of Personality Disorders. 2005; 19:110-130. [PubMed: 15899712]

Widiger, TA.; Smith, GT. Personality and psychopathology. In: John, OP.; Robins, RW.; Pervin, LA., editors. Handbook of personality: Theory and research. 3rd. New York: Guilford Press; 2008. p. 743-769.

Wing L, Gould J. Severe impairments of social interaction and associated abnormalities in children: Epidemiology and classification. Journal of Autism and Developmental Disorders. 1979; 9:1129. [PubMed: 155684]

Wright AG, Thomas KM, Hopwood CJ, Markon KE, Pincus AL, Krueger RF. The hierarchical structure of DSM-5 pathological personality traits. in press.

Yirmiya N, Erel O, Shaked M, Solomonica-Levi D. Meta-analyses comparing theory of mind abilities of individuals with autism, individuals with mental retardation, and normally developing individuals. Psychological Bulletin. 1998; 124:283-307. [PubMed: 9849110]

Zahavi D. Complexities of self. Autism: The International Journal of Research and Practice. 2010; 5:547-551. [PubMed: 20841340]

Zweig-Frank H, Paris J. The five-factor model of personality in borderline and nonborderline personality disorders. Canadian Journal of Psychiatry. 1995; 40:523-526. 
Table 2

Studies 1 and 2: Do Personality Traits Predict Within-Group Variability in Autism Symptom Severity?

\begin{tabular}{|c|c|c|c|c|}
\hline \multirow[b]{3}{*}{ Big Five dimension } & Study 1 & \multicolumn{3}{|c|}{ Study 2} \\
\hline & \multirow{2}{*}{ Clinician-reported ADOS-G } & \multirow{2}{*}{ Clinician-reported ADOS-G } & \multicolumn{2}{|c|}{ Parent-reported SCQ } \\
\hline & & & ASD & TD \\
\hline \multicolumn{5}{|l|}{ Extraversion } \\
\hline Self-report & -.01 & -.12 & -.01 & -.19 \\
\hline Parent report & -- & -.03 & -.14 & -.23 \\
\hline \multicolumn{5}{|l|}{ Agreeableness } \\
\hline Self-report & .21 & -.07 & .13 & .10 \\
\hline Parent report & -- & -.02 & -.02 & -.03 \\
\hline \multicolumn{5}{|l|}{ Conscientiousness } \\
\hline Self-report & .22 & -.04 & .12 & .11 \\
\hline Parent report & -- & -.16 & -.23 & -.13 \\
\hline \multicolumn{5}{|l|}{ Neuroticism } \\
\hline Self-report & $-.37^{*}$ & .17 & .05 & .07 \\
\hline Parent report & -- & .13 & $.35^{*}$ & -.03 \\
\hline \multicolumn{5}{|l|}{ Openness } \\
\hline Self-report & -.20 & -.16 & .06 & -.04 \\
\hline Parent report & -- & -.09 & $-.36^{*}$ & $-.33^{*}$ \\
\hline
\end{tabular}

Note. $n=37$ for ASD adult self-report (Study 1); $n=50$ for ASD and 50 for TD for child self-report, and $n=50$ for ASD and 49 for TD for parent report (Study 2). ASD = Autism Spectrum Disorder; TD = Typically Developing. ADOS-G = Autism Diagnostic Observation Schedule-Generic (Lord et al., 2000); SCQ = Social Communication Questionnaire (Rutter et al., 2003).

$*$

$p<.05$;

*** $p<.01$ 


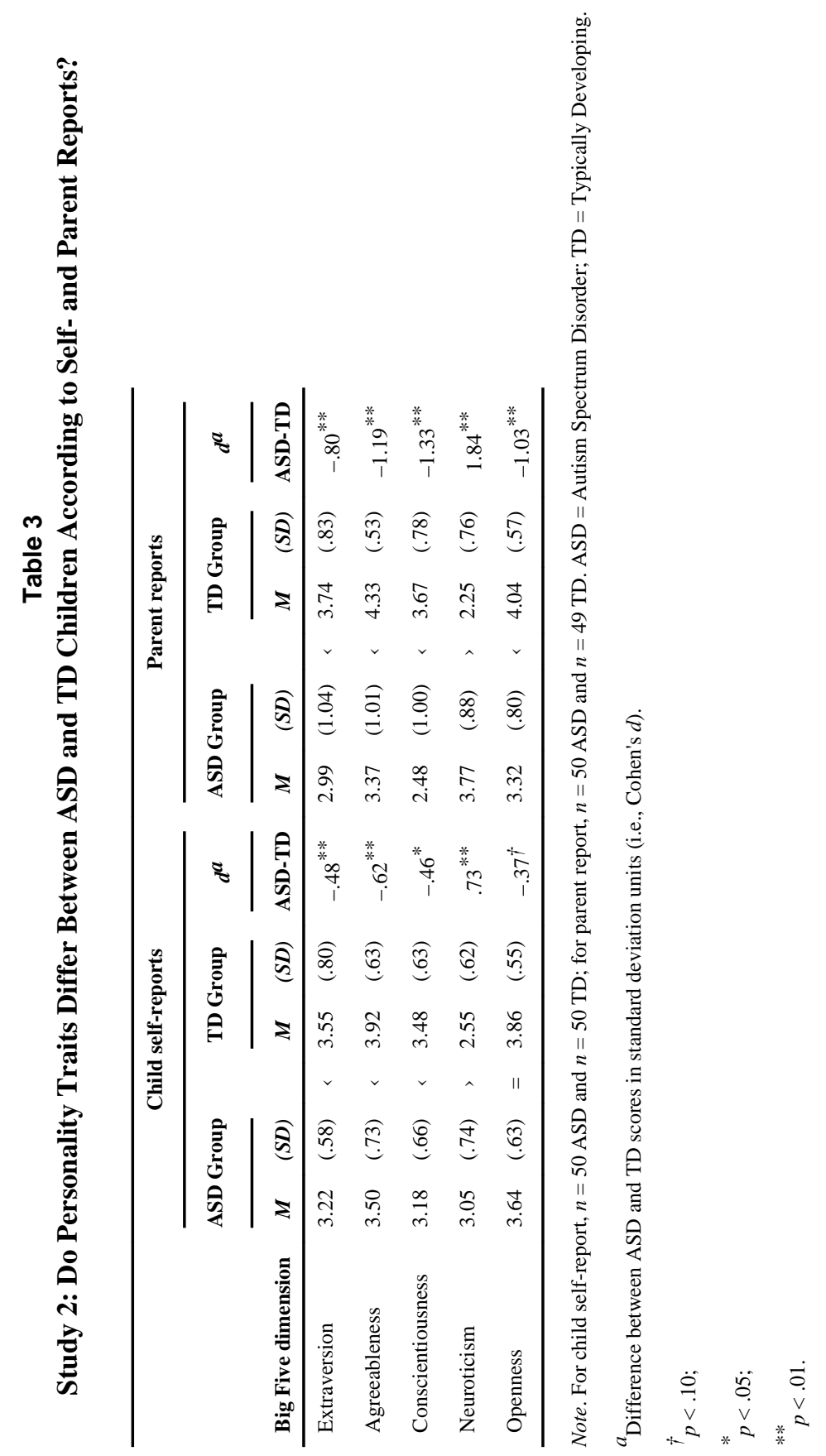


Table 4

Study 2: Do the Personality Correlates of Maladjustment Differ for ASD and TD Children?

\begin{tabular}{lccccc}
\hline & \multicolumn{2}{c}{ Internalizing } & & \multicolumn{2}{c}{ Externalizing } \\
\cline { 2 - 3 } Big Five dimension & ASD & TD & & ASD & TD \\
\hline Extraversion & & & & \\
Child self-report & -.23 & $-.32^{*}$ & & -.19 & -.02 \\
Parent report & -.22 & $-.39^{* *}$ & .22 & -.01 \\
Agreeableness & & & & \\
Child self-report & $-.34^{*}$ & .22 & & $-.29^{* *}$ & -.03 \\
Parent report & $-.50^{* *}$ & -.08 & & $-.65^{* *}$ & $-.40^{* *}$ \\
Conscientiousness & & & & \\
Child self-report & -.13 & -.02 & & -.14 & $-.38^{* *}$ \\
Parent report & $-.28^{\dagger}$ & -.21 & & $-.45^{* *}$ & $-.43^{* *}$ \\
Neuroticism & & & & \\
Child self-report & $.40^{* *}$ & .05 & $.45^{* *}$ & $-.25^{\dagger}$ \\
Parent report & $.70^{* *}$ & $.54^{* *}$ & $.40^{* *}$ & .16 \\
Openness & & & & .02 & -.04 \\
Child self-report & .12 & -.09 & .02 & $-.27^{\dagger}$ \\
Parent report & -.09 & $-.35^{*}$ & .03 & \\
\hline
\end{tabular}

Note. For child self-report, $n=50 \mathrm{ASD}$ and $n=50 \mathrm{TD}$; for parent report, $n=50 \mathrm{ASD}$ and $n=49 \mathrm{TD}$. ASD $=$ Autism Spectrum Disorder; TD $=$ Typically Developing.

${ }^{\dagger} p<.10$

* $p<.05$

$* *$

$p<.01$. 
Table 5

Study 2: Do ASD Individuals Have Less Self-Insight Relative to TD Individuals Using a Variable-Centered Approach to Self-Other Agreement?

\begin{tabular}{lcccc}
\hline & \multicolumn{4}{c}{ Child-Parent Agreement } \\
\cline { 2 - 5 } Big Five dimension & Total & ASD & TD & $\boldsymbol{Z}^{\boldsymbol{a}}$ \\
\hline Extraversion & $.57^{* *}$ & $.38^{* *}$ & $.71^{* *}$ & $2.34^{*}$ \\
Agreeableness & $.43^{* *}$ & $.34^{*}$ & $.36^{*}$ & .11 \\
Conscientiousness & $.38^{* *}$ & .19 & $.48^{* *}$ & 1.59 \\
Neuroticism & $.47^{* *}$ & $.42^{* *}$ & .23 & 1.02 \\
Openness & $.39^{* *}$ & $.34^{*}$ & $.38^{*}$ & .22 \\
\hline
\end{tabular}

Note. $N=50$ for ASD group and 49 for TD group. ASD = Autism Spectrum Disorder; TD = Typically Developing.

${ }^{a}$ Z-test for the difference between ASD and TD child-parent correlations.

* $p<.05$;

$* *$ p $<.01$. 
Table 6

Study 2: Do ASD Individuals Have Less Self-Insight Relative to TD Individuals Using a Person-Centered Approach to Self-Other Agreement?

\begin{tabular}{lccc}
\hline & \multicolumn{2}{c}{ Mean Profile Correlation } \\
\cline { 2 - 4 } Agreement index & Total & ASD & TD \\
\hline Overall agreement & .49 & .32 & .67 \\
Distinctive agreement & .36 & .33 & .38 \\
Normative agreement-Self & .51 & .38 & .64 \\
Normative agreement-parent & .57 & .41 & .75 \\
\hline Note. $N=50$ for ASD group and 49 for TD group. ASD $=$ Autism Spectrum Disorder; TD = Typically Developing. \\
$*$ \\
$p<.05 ;$ \\
$* *$ \\
$p<.01$.
\end{tabular}

